Date: 02/21/17

\title{
Dynamics of water and salt exchange at Maryland Coastal Bays
}

\author{
Xinyi Kang ${ }^{\mathrm{a}}$, Meng Xia ${ }^{\mathrm{a}^{*}}$, Joseph S. Pitula ${ }^{\mathrm{a}}$, Paulinus Chigbu ${ }^{\mathrm{a}}$
}

${ }^{a}$ Department of Natural Sciences, University of Maryland Eastern Shore, Princess Anne, Maryland, USA

NSF CREST Center for the Integrated Study of Coastal Ecosystem Processes and Dynamics in the Mid-Atlantic Region

\section{Corresponding author:}

E-mail address: mxia@umes.edu (M. Xia)

Estuarine, Coastal and Shelf Science (In Revision)

(C) 2017. This manuscript version is made available under the Elsevier user license http://www.elsevier.com/open-access/userlicense/1.0/ 


\begin{abstract}
The exchange processes between the Maryland Coastal Bays system (MCBs) and their adjacent coastal ocean were simulated using a three-dimensional unstructured-grid based hydrodynamic model, which was validated by observed data including water level, current velocity and salinity. Idealized experiments were then carried out to investigate the impact of wind forcing on water exchange and salt flux. Through these experiments, the exchanges between the MCBs and coastal ocean were investigated at two inlets (Ocean City Inlet and Chincoteague Inlet). Given that winds and tides are two key external forces known to impact estuarine dynamics, the effect of each individual force on the exchange processes was studied to evaluate the corresponding influence on the inlet dynamics. It was found that wind forcing significantly impacts the inlet dynamics: the effect of wind directions on exchange processes under strong wind speeds is substantial; for example, northwesterly winds push flux to the southern part of the bays, while southwesterly winds pile up flux towards northern Chincoteague Bay. The effect of wind forcing on the exchange dynamics becomes stronger with the augmentation of its speed. Meanwhile, tidal forcing is the major driver of exchange dynamics at weak wind speeds (e.g., $3 \mathrm{~m} / \mathrm{s}$ ), and its effect on exchange process gradually weakens with stronger wind speeds (e.g., $7 \mathrm{~m} / \mathrm{s}, 15 \mathrm{~m} / \mathrm{s}$ ). In addition, sensitivity tests elucidated that closing either inlet results in a significant impact on the water elevation, current velocity and salinity nearby the relevant cut-off inlet areas.
\end{abstract}

Key words: The Maryland Coastal Bays system; Hydrodynamic model; Inlets; Water exchange; Salt flux. 


\section{Introduction}

Exchange between an estuary and its adjacent coastal ocean determines the water mass transport of the lateral and vertical structure across inlet areas (Zhu et al., 2015; ValleLevinson et al., 1996; Valle-Levinson and Lwiza, 1995). The transition zone between them is subject to oceanic influences, such as tides, waves and the intrusion of water, and to limnetic influences including the freshwater discharge. The health of an estuarine ecosystem depends on such estuary-ocean exchange processes, which are associated with water quality, pollutants and primary production, etc. (Arega et al., 2008; Kimmerer et al., 2014; Dettmann, 2001). In view of the importance of estuaries, it is crucial to perform a comprehensive study into their physical exchange and dynamic processes.

The combined physically interactive forces, such as stratification, winds, river discharge, and tides (Kim and Park, 2012; Xia et al., 2011; MacCready et al., 2009; Xue et al., 2009; Wang et al., 2010; Valle-Levinson et al., 2001; Whitney and Garvine, 2006), govern the dynamics of estuary circulation. Winds and tides are particularly important factors that influence the exchange dynamics of estuaries and the coastal ocean (Kraines et al., 1999; Herrling and Winter, 2015; Pfeiffer-Herbert et al., 2015). Quantitative analysis of water exchange and salt flux helps to explain the dynamics of many estuaries under the effect of wind forcing, such as in Mobile Bay (Kim and Park, 2012), Perdido Bay (Xia et al., 2011), Baltic Sea and Sakgerrak Strait (Stigebrandt, 1983), and Shark Bay (Hetzel et al., 2015), while these studies were based on the simple two-layer model or highly developed numerical models with structured grids. 
The Maryland Coastal Bays system (MCBs), a two-inlet estuarine system, are crucial to the agriculture, fishing, recreation, and tourism industries in Maryland, and they also provide important habitats for summer flounder (Paralichthys dentatus), blue crab (Callinectes sapidus), black sea bass (Centropristis striata) and many other commercially important species (e.g., Cynoscion regalis, Anguilla rostrata, Pomatomus saltatrix, etc.) (Love et al., 2009). They are a vital part of Maryland Eastern Shore's economy and quality of life. At the same time, the MCBs face problems of degraded water quality and declining biodiversity (Jesien et al., 2009), and they are especially vulnerable to environmental and human-induced pressures. These issues are closely associated with the physical exchange process between the bays and the coastal ocean. However, until now, there were few relevant discussions on the exchange processes of the MCBs (Pritchard, 1960; Wang et al., 2013). The dynamics of water and salt exchange through inlets in the MCBs still remain unresolved with limited discrete observed data on scalar variables (water elevation, current velocity, salinity and temperature), which makes the application of a numerical model to be a reasonable alternative. These issues motivated us to seek a better understanding of the water exchange and salt flux dynamics impacted by physical forcing such as winds and tides, particularly for the MCBs, a two-inlet estuarine system.

The unique physical structure of estuarine systems is one difficulty in modeling estuarine circulation and bay-ocean exchange. Estuarine circulation and water mass transport are strongly affected by the intricacies of a system's unique shape and bathymetry (Bao et al., 2000), and this requires a three-dimensional (3D) understanding of an estuarine system. Thus, highly developed 3D numerical models capable of simulating flow pattern induced 
by winds, tides, and density gradients over a complex geometry and bathymetry, are the most appropriate tools for the study of such systems (Chen et al., 2008; Safak et al., 2015, Yang and Wang, 2013; Lemagie and Lerczak, 2015). In order to accurately simulate the relevant physical features of estuarine and coastal oceans in response to winds and tides, numerical models must be able to resolve the complex geometry and bathymetry precisely and effectively.

Over the past few years, an unstructured grid, finite-volume, and 3D hydrodynamic model - Finite Volume Coastal Ocean Model (FVCOM) (Chen et al., 2006) has been successfully used in various coastal, oceanic and lake areas, such as Chesapeake Bay (Jiang and Xia, 2016), Tampa Bay (Weisberg and Zheng, 2006), Gulf of Maine and New England Shelf (Chen et al., 2011), and Lake Erie (Niu et al., 2015). FVCOM is particularly easy to follow the complex shoreline and inlet areas, therefore, it was selected for the MCBs. This study aims to: (1) investigate the influence of inlets on the hydrodynamics of the bays; (2) shed light on the role of wind forcing in controlling water exchange and salt flux through inlets between the MCBs and the adjacent coastal ocean; (3) quantify the influence of each type of physical forcing (winds and tides) on water exchange and salt flux via the two inlets independently.

\section{Methodology}

\subsection{Study Area}

The MCBs are located in the eastern part of the mainland of Worcester County, Maryland, adjacent to the Atlantic Ocean. They include Assawoman Bay (AB), Isle of 
Wight Bay (IoWB), Saint Martin's River (SMR), Sinepuxent Bay (SB), Newport Bay (NB), and Chincoteague Bay (CB), extending north from the Delaware-Maryland border, to Virginia in the south (Fig. 1a). The surface area of the MCBs along with their watershed is approximately $453 \mathrm{~km}^{2}$ with a relatively shallow average water depth of around $1 \mathrm{~m}$, except in the navigation channels and the inlet regions (Krantz et al., 2009; Boynton et al., 1996; Wazniak et al., 2005). The shallow nature of this system leads to a well-mixed water column being typical inside the MCBs. The MCBs interact with the adjacent Atlantic Ocean through two inlets: Ocean City Inlet (OCI) in Ocean City, Maryland and Chincoteague Inlet (CI) in the south of the CB in Virginia (Fig. 1a). The average depth for the OCI and CI are roughly $7.3 \mathrm{~m}$ and $4 \mathrm{~m}$, respectively, with the OCI being a much narrower inlet (Fig. 1e and f). A slow water replacement time is the response to limited freshwater discharge and constricted inlets. Residence times vary from 9.45 days for the IoWB (Lung, 1994) to as long as 63 days for the CB (Pritchard, 1960). The spatial salinity distribution of the MCBs is determined by freshwater discharge, wind stirring and tidal mixing, depending on the distance from inlets as a result of the weakened effect of salt intrusion through inlets (Pritchard, 1960).

\subsection{Model Description}

FVCOM is a finite volume, free-surface, 3D hydrodynamic model (Chen et al., 2006). Using the unstructured horizontal grid and sigma vertical coordinate, it has the potential to accurately follow the complex coastline and the basin bathymetry, which makes it appropriate to apply to the MCBs. It employs the Mellor-Yamada level 2.5 and 
Smagorinsky turbulent closure parameterization for vertical and horizontal turbulence mixing (Mellor and Yamada, 1982; Galperin et al., 1988; Smagorinsky, 1963).

In FVCOM, the bottom stress is calculated by a quadratic formula in the form of $\left(\tau_{b x}, \tau_{b y}\right)=\rho C_{d}\left(u_{b}, v_{b}\right) \sqrt{u_{b}^{2}+v_{b}^{2}}$

where $u_{b}$ and $v_{b}$ are the bottom current velocity along the axis of $x$ and $y$; and $C_{d}$ is the bottom drag coefficient that is determined by matching a logarithmic bottom layer to the model at a height $z_{b}$ above the bottom, i.e.,

$C_{d}=\max \left[\frac{\kappa^{2}}{\ln \left(\frac{b_{b}}{z_{0}}\right)^{2}}, 0.0025\right]$

where $\kappa=0.4$ is the von Karman constant, and $z_{0}$ is the bottom roughness parameter. Due to the overall shallowness of the MCBs, $z_{0}$ was set to be $0.0036 \mathrm{~m}$.

The model domain (Fig. 1b and d) stretches from Delaware in the north, to Virginia in the south. The mesh is comprised of 7,332 nodes and 12,428 elements in total, and extends from the U.S. East Coast out approximately $16.8 \mathrm{~km}$ into the adjacent Atlantic Ocean. This model grid is based on the similar one of Wang et al. (2013), and it was modified to fit for FVCOM.

Considering the complex bathymetry and the irregular shorelines of the MCBs, a high level of grid detail is required to execute the related simulations (Fig. 1d). High spatial resolution was used in the areas of interest, such as inlet regions $(0.04-0.37 \mathrm{~km}$, Fig. 1e and f). A coarse spatial resolution was implemented in the middle regions of the MCBs and the adjacent coastal Atlantic Ocean (0.85-1.87 km, Fig. 1d). To investigate the 
presence of inlets on the hydrodynamics of the bays, either inlet (the OCI or CI) was then closed (Fig. 1g and h). At the same time, there were 6 uniformly vertical sigma levels following the basin topography. To ensure the numerical stability, a small time step is often required; in this study, a 1-s time step was used for all model simulations.

\subsection{Initial and Boundary Conditions, External Forcing, and Observation Data}

The hydrodynamic model was driven by river inputs, sea surface meteorological forcing and open boundary equilibrium tides. Three river inputs were included in the model (Fig. 1b), and the daily discharge flux was obtained from the U.S. Geology Survey (USGS). Freshwater discharge coming from numerous small rivers into the MCBs is relatively limited (Krantz et al., 2009). Salinity was set to constant value of 32.45 at the open boundary, and the spatial salinity distribution of the MCBs was obtained from Wang et al. (2013). The related surface meteorological inputs including wind fields, relative humidity, air temperature, air pressure at sea level, and downward long-wave/short-wave radiation were collected from the North American Regional Reanalysis (NARR) in the National Oceanic and Atmospheric Administration (NOAA) Earth System Research Laboratory, and these data were applied every 3 hours to force the model. The predicted tidal inputs were interpolated from the Oregon State University global inverse tidal model TPXO 7.2 (Egbert and Erofeeva, 2002), and eight harmonic tidal components including four semidiurnal constituents $\left(M_{2}, N_{2}, S_{2}\right.$ and $\left.K_{2}\right)$ and four diurnal constituents $\left(O_{1}, P_{1}, K_{1}\right.$ and $Q_{1}$ ) were imposed at the open boundary. In order to calibrate and validate the model results, observed hourly water elevation data was obtained from NOAA/National Ocean

Service and Maryland Department of Natural Resources (MD-DNR). Detailed 
information about the measurements of the observed water levels inside the MCBs was illustrated in Wells et al. (2004). The ADCP deployed along the IoWB Channel was mounted $0.5 \mathrm{~m}$ above the bottom with up-looking $600 \mathrm{kHz}$ RD Instruments (Fig. 1c). Observed salinity data were obtained from MD-DNR.

\subsection{Experiment Designs}

Sept. 2, 00:00:00 UTC to Sept. 17, 24:00:00 UTC 2004 (Modified Julian Day 246 to 261 since 2004/01/01) with sufficient observed data was chosen for model calibration and validation. Given that the model has a good performance for validation in Sept. 2004 (Section 3), all the sensitivity experiments were conducted using this validated model. The model started Sept. 1, 00:00:00 UTC with one-day spin-up time after giving the initial condition.

The two inlets (OCI and CI) are the important entrances for the physical exchange process between the bays and the adjacent coastal ocean. Sensitivity tests without any inlet were designed to investigate the influence of inlets on the hydrodynamic parameters (e.g., water elevation, current velocity and salinity) with the help of this validated model during the same model validation time period.

Surface wind forcing along the MCBs has distinct seasonality. In the summer, weak (3 $\mathrm{m} / \mathrm{s})$ to mild $(7 \mathrm{~m} / \mathrm{s})$ prevailing winds usually blow from southwest (Fig. 2a); while in the winter, strong northwesterly winds $(15 \mathrm{~m} / \mathrm{s})$ are dominant (Fig. 2b). Based on the actual wind climatology of the MCBs, two typical wind directions: along-shore southwesterly 
(SW) winds and across-bay northwesterly (NW) winds were applied to the study area, with wind speeds ranging from $3 \mathrm{~m} / \mathrm{s}$ to $15 \mathrm{~m} / \mathrm{s}$ during Sept. 10, 00:00:00 UTC to Sept. 14, 00:00:00 UTC 2004 (Table 1: Run 2 to Run 11). At the same time, these simulated cases were still under the influence of tides. Also incorporated was a benchmark case (Run 1 from Table 1) without winds, tides and river inflow during the same study time. Due to the longer residence times of the MCBs, small time step outputs are needed to evaluate the response of water exchange and salt flux affected by different physical forcing. Here, we set the time interval for outputs to be 30 -min. In order to avoid the effect of initial condition on the result of flux dynamics, the outputs from Sept. 11, 00:00:00 UTC to Sept. 14, 00:00:00 UTC, total three days, were chosen for the flux study. Since winds and tides strongly regulate the estuarine exchange, the effect of each physical force on the exchange processes was studied to evaluate the individual influence on the inlet dynamics (Run 12 to Run 18 in Table 1).

\subsection{Water Exchange and Salt Flux Calculations}

A quantitative assessment method for calculating water exchange and salt flux was applied to the inlet areas of the MCBs to establish a better understanding of flux exchange between the bays and the adjacent coastal ocean regions. Previous studies have investigated water and salt exchange in estuaries using two-dimensional (2D) or 3D model simulations (Stigebrandt, 1983; Gustafsson, 2000; Zheng et al., 2003; Bilgili et al., 2005; Liu et al., 2004; Hetzel et al., 2015; Dufresne et al., 2014; Cianelli et al., 2015). Water exchange and salt flux were calculated based on the sensitivity cases from Table 1. 
The average water and salt flux calculation is described in detail by Xia et al. (2011).

Water Flux $=\int_{t_{1}}^{t_{2}} \int_{-h}^{\eta} \int_{x_{1}}^{x_{2}} v d x d h d t / \int_{t_{1}}^{t_{2}} d t$

Salt Flux $=\int_{t_{1}}^{t_{2}} \int_{-h}^{\eta} \int_{x_{1}}^{x_{2}} S \cdot v d x d h d t / \int_{t_{1}}^{t_{2}} d t$

where $v$ is the current velocity that is perpendicular to the direction of the inlet, $h$ is the depth of the water, $\eta$ is the water elevation, $S$ is the salinity, $x_{1}$ and $x_{2}$ are the left and right horizontal locations of the inlet, $t_{1}$ and $t_{2}$ are the starting time and ending time for the integral period; $d x$ is the grid width across the inlet, $d h$ is the depth along the vertical direction and $d t$ is the time step.

\subsection{Water Level Attenuations and Time Lags}

Signal attenuation $(\alpha)$ is defined by the quotients of the standard deviations (SDs) at different sites when water level propagates into the MCBs through inlets, given the definition below.

$\alpha=\left(1-\frac{S D_{2}}{S D_{1}}\right) \times 100$

where $S D_{1}$ is the signal standard deviation at inlet sites and $S D_{2}$ is the signal standard deviation at the other site inside the bay areas. The higher value of $\alpha$ means the signal is strongly attenuated through propagation. The detrended diurnal tidal signal is only applicable to this method. Sept. 13, 00:00:00 UTC to Sept. 15, 24:00:00 UTC 2004 was selected for the calculation of signal attenuations. The diurnal tidal signal was extracted by using the T_tide Harmonic Analysis Toolbox of Matlab (Pawlowicz et al., 2002). The cross-correlation method was applied to the time lag calculation for the same data period. 


\subsection{Statistics Parameters}

A quantitative comparison between the model hindcast and the observed data was used to appraise the model performance. Correlation coefficients $(R)$, mean absolute error $(M A E)$, root mean square deviation $(R M S D)$ and relative square error $(R S E)$ were applied and defined as below.

$R=\frac{\sum_{i=1}^{N}\left(M_{i}-\bar{M}\right)\left(O_{i}-\bar{O}\right)}{\sqrt{\frac{1}{N} \sum_{i=1}^{N}\left(M_{i}-\bar{M}\right)^{2}} \sqrt{\frac{1}{N} \sum_{i=1}^{N}\left(O_{i}-\bar{O}\right)^{2}}}$

$M A E=\frac{1}{N} \sum_{i=1}^{N}\left|M_{i}-O_{i}\right|$

$R M S D=\sqrt{\frac{1}{N} \sum_{i=1}^{N}\left(O_{i}-M_{i}\right)^{2}}$

$R S E=\frac{\sum_{i=1}^{N}\left(O_{i}-M_{i}\right)^{2}}{\sum_{i=1}^{N}\left(\bar{O}-O_{i}\right)^{2}}$

where $M$ is the model hindcast, and $O$ is the observed data. These statistical measures are widely used in coastal ocean model evaluations (e.g., Liu et al., 2009).

\section{Model Calibration and Validation}

\subsection{Model Calibration}

Five observed water elevation stations (Fig. 1b): Ocean City Inlet (E1) located at Ocean City; Snug Harbor (E2) and South Point (E3), both located in the SB; Public Landing (E4) located in the upper middle region of the CB, and Harbor of Refuge (E5) located at the south of Chincoteague Island, have adequate information on the range of tides in the MCBs. At the beginning, we investigated the influence of bottom roughness parameter on the water level simulations. A list of sensitivity tests with different bottom roughness parameters $\left(z_{0}\right)$, varying from $0.001 \mathrm{~m}$ to $0.004 \mathrm{~m}$ with an interval of $0.001 \mathrm{~m}$, was 
conducted during the study period. All of these simulations showed a similar trend for the water level at the study sites (Fig. 3a, b, c, d, and e). There was no significant difference between the simulated water levels at the OCI using different bottom roughness parameters (Fig. 3a). Higher bottom roughness parameters $\left(z_{0}=0.003 \mathrm{~m}, 0.004 \mathrm{~m}\right)$ contributed to the good agreement between the simulated and observed water level at Harbor of Refuge (Fig. 3e). However, the variance between the observed and simulated water level was found inside the bay areas, especially for the smaller bottom roughness parameters of $0.001 \mathrm{~m}$ and $0.002 \mathrm{~m}$ (Fig. 3b, c and d). Then, another nine sensitivity experiments with different bottom roughness parameters, ranging from $0.0031 \mathrm{~m}$ to $0.0039 \mathrm{~m}$, with an interval of $0.0001 \mathrm{~m}$ were performed. Ultimately, the bottom roughness of $0.0036 \mathrm{~m}$ was selected for the MCBs with the best performance of all the tests (Table 2).

Based on these sensitivity tests, it concludes that the water level inside the MCBs is very sensitive to the bottom roughness parameter. The uniform bottom roughness parameter can't be used to depict the whole MCBs, which means the bottom roughness parameter varies spatially. However, there is less sediment documentation for the MCBs, indicating that the specific bottom roughness parameters can't be set very precisely.

\subsection{Model Validation}

The simulated water level demonstrates that tide ranges inside the MCBs were much smaller (Fig. 3g, h and i) compared with the other two stations close to inlet areas (Fig. 3f and $\mathrm{j}$ ). The simulated water level at inlets (Ocean City Inlet at OCI and Harbor of Refuge 
at CI) was in good agreement with observed water level (Fig. 3f and j). Even though the model caught the base line of observed water level, it over-predicted the water elevation by approximately $0.2 \mathrm{~m}$ at South Point (Fig. 3h) and $0.1 \mathrm{~m}$ at Public Landing (Fig. 3i), and underestimated by approximately $0.2 \mathrm{~m}$ at Snug Harbor (Fig. 3g). The correlation coefficients between modeled and observed water elevations were above 0.8 , and the $R M S D$ s were almost less than $10 \mathrm{~cm}$ (Table 2: orange squares). The $R S E$ indicates the significance of the difference between the modeled and observed data at each site. The larger RSE was found at sites inside the MCBs with 0.51, 0.64 and 0.55 for Snug Harbor, South Point and Public Landing, respectively (Table 2: orange squares). The larger variance is likely due to the importance of the bottom roughness parameter and the combined factors of the irregular coastline shape with the complex bathymetry of the MCBs when water level propagates from the coastal ocean to the bay areas.

There was a clear attenuation trend for the tidal signals through the water level propagation from inlets into the bays. The signal at diurnal frequencies attenuated by 51.3\% and 64.5\% from the OCI to Snug Harbor and South Point, respectively (Table 3: purple squares), as calculated by the observed water level. This indicates that $48.7 \%$ and $35.5 \%$ of tidal signal reached to Snug Harbor and South Point through a tidal propagation. This propagation took around 4 hours to travel from the OCI to South Point. Meanwhile, the diurnal frequencies attenuated by 55.5\% from Harbor of Refuge to Public Landing with the travelling time of 1.5 hours calculated by the observed water level (Table 3: purple squares). However, the diurnal frequencies attenuated weaker at South Point from Harbor of Refuge with the attenuation of 50.9\% of tidal signals (Table 3: 
purple squares), indicating that the water level at South Point is also influenced by the tidal propagation through the OCI. The signal attenuation and time lag calculated by the simulated water level depicts a similar attenuation trend as those calculated by the observed data (Table 3: purple squares). However, the differences in the signal attenuation trend and time lag calculated by the two types of data are probably caused by the water level biases between them. Our result has the similar attenuation trend as calculated by Casares-Salazar and Mariño-Tapia (2016) where water level propagates from the coastal lagoon mouth to the head in Celestun, Mexico with a tidal signal attenuation. The reasonable agreements between the modeled and observed water level data revealed that the tidal forcing at the open boundary, and the local settings such as topography and winds, allowed for the good performance of water elevation simulation.

The depth-averaged longitudinal (along-channel) current velocity along the IoWB Channel (Fig. 1c) was compared between the observed and modeled data, and the model produced the current velocity variation well (Fig. 4). The current velocity along the IoWB Channel reached the maximum speed of $1 \mathrm{~m} / \mathrm{s}$ with a high correlation coefficient of 0.98 . MAE, RMSD, and $R S E$ were $\sim 14.34 \mathrm{~cm} / \mathrm{s}, 11.21 \mathrm{~cm} / \mathrm{s}$ and 0.04 , respectively (Fig. 4b).

Given the dates and locations of observed salinity data in Sept. of 2004 from MD-DNR, five stations were selected to exhibit the spatial salinity distribution of the MCBs: S1, S2 and S3 in the northern region of the MCBs, S4 in north NB and S5 in south CB (Fig. 1b). Wind fields at the five salinity stations were basically close to each other (Fig. 5a, b, c, d 
and e). The average wind magnitudes of $\mathrm{S} 1$ to $\mathrm{S} 5$ were $3.67,3.73,3.78,3.77,3.86 \mathrm{~m} / \mathrm{s}$ with the maximum wind speeds of $8.88,8.91,8.95,8.87$ and $8.80 \mathrm{~m} / \mathrm{s}$, respectively. With similar wind fields, different salinity patterns occurred at the five salinity stations, indicating that freshwater discharge and salt intrusion from inlets are the primary driving force of the salinity pattern of the MCBs under normal weather conditions.

Salinity at S3 near the OCI was higher and more stable (Fig. 5h) than the other sites inside the bay areas (Fig. 5f, g, i, and j), and is mainly determined by the salt intrusion from the coastal ocean. Salinity at S1 in the SMR (Fig. 5f) ranged from 20 to 25, indicating that this lower salinity is more affected by the river discharge from the small streams in the SMR (Fig. 1b, R2: USGS 0148471320). Salinity at S2 around Turville Creek (Fig. 5g) ranged from 10 to 20, with a larger variation between the observed and simulated salinity data from Julian Day 251 to 253, indicating that Turville Creek was affected by the freshwater discharge from the small streams in the IoWB. However, there is no available observed fresh water data near Turville Creek, which may lead to the salinity overestimation at S2. Salinity at S4 in the NB (Fig. 5i) was approximately 25, indicating that low-saline water from streams of the NB causes this low salinity pattern (Fig. 1b, R3: USGS 01484719). Nevertheless, low-saline water from the NB typically does not influence the salinity in the southern part of the CB directly (Wang et al., 2013). At station S5 (in the center of the CB), the model overestimated the salinity with mean absolute error of around 3 (Fig. 5j). USGS offers a reasonable explanation for this overestimation, which may be attributable to the ground water recharge of the MCBs that was not included in this hydrodynamic model (Manheim, 2002). Our findings are 
consistent with the findings in Wang et al. (2013), as river discharge and salt intrusion from inlets are responsible for the salinity variation of the MCBs.

A good reproduction of water elevation, current velocity and salinity lends credence to the performance of this hydrodynamic model, which is encouraging in light of our goal of simulating water/salt exchange dynamics of the MCBs. Overall, this 3D hydrodynamic model has the ability to perform well based on the methods described in Section 2.3.

\section{Discussion}

\subsection{Water Elevations, Current Velocity and Salinity Simulation Without the OCI or CI}

The simulations demonstrate that the water elevation at both inlets is strongly controlled by the tidal propagation through its specific closest inlet (Fig. 3k and o). According to the correlation analyses, the simulated water elevation at Ocean City Inlet without the CI, and at Harbor of Refuge without the OCI are highly positively correlated with the observed data, as the correlation coefficients are 0.96 and 0.95 respectively, with low $p$ values less than 0.001 indicating its significance at a 95\% confidence level. The high correlation coefficient (0.78) with low $p$ value for the case without the $\mathrm{CI}$ and low correlation coefficient (0.19) with high $p$ value for the case without the OCI provide the support for the claim that the tidal propagation from the OCI is the major source to Snug Harbor (Fig. 31). The water level at Public Landing is mainly dependent on the tidal propagation through the CI (Fig. 3n). While, South Point is determined by the water level propagation from the coastal ocean into the bays through both inlets. The tidal 
propagation through the $\mathrm{CI}$ is the dominant factor to the water level at South Point as the correlation coefficients of the case without the OCI and without the CI were 0.78 and 0.41 , respectively, with low $p$ values (Fig. $3 \mathrm{~m}$ ). This is due to the wider width of the CI and the more regular shape of the $\mathrm{CB}$ towards to the north of the MCBs.

When the CI is closed, the tidal signal can only transport from the OCI into the bays. The calculated attenuations of water levels from the OCI to the other sites inside the bays manifested that there are only $4.5 \%$ of tidal (diurnal) signal left at the Harbor of Refuge (Table 3: orange squares) impacted by the constricted OCI and the irregular coastline shape with the complex bathymetry of the SB (Fig. 1b). It takes about 9 hours to propagate from the OCI to the south end of the CB. Without the OCI, an apparent attenuation tendency can be observed from the CI to the north of the bays. More tidal information (14.7\%) remains at the OCI with the travelling time of 11 hours (Table 3: green squares). This is due to the wider width of the $\mathrm{CI}$ and more regular shape of the $\mathrm{CB}$, allowing more tidal information transport to the north of the MCBs. $9.9 \%$ and $37.3 \%$ of tidal signals from the water level propagation through the OCI and the CI leave at South Point (Table 3: orange/green squares), respectively, which indicates that the tidal propagation through the $\mathrm{CI}$ is a major source to the water level at South Point. This attenuation trend for the water level propagation from inlets to the bay areas was also supported in the study of the similar attenuation trend through water level propagation from the coastal lagoon mouth to the head in Celestun, Mexico (Casares-Salazar and Mariño-Tapia, 2016). 
Closing either inlet influences the current velocity along the IoWB Channel greatly (Fig. 4a). Without the OCI, there is rather slow water movement along the IoWB Channel. However, by closing the CI, the current velocity has $\sim 50 \%$ reduction on the current velocity magnitude.

Salinity at S3 near the OCI could tell the significance of the OCI on the exchange process. Without the OCI, salinity at S3 declines significantly, as there is no exchange for the salt water from the coastal ocean moving into the bays (Fig. 5h). Similarly, salinity at S2 around Turville Creek also drops by 4 (Fig. 5g), as the location of S2 is close to the OCI (Fig. 1b). However, the other observed salinity stations are far from the inlet areas, and there is no significant salinity variation between different sensitivity cases when closing either inlet (Fig. 5f, i and j), as the salt intrusion is weaker far from inlet areas, which can be gained from the spatial salinity of the MCBs.

The spatial salinity of the MCBs depicts the influence of either inlet intuitively (Fig. 6a, b and c). Cutting off the OCI would result in the lowering of salinity in the upper bay areas (Fig. $6 \mathrm{~b}$ and d). Salt water can only move into the MCBs through the CI, raising the salinity of most parts of the CB (Fig. $6 \mathrm{~b}$ and d). On the other hand, without the CI, the salinity of the areas close to the CI drops, as the cut-off CI stops salt water from moving into the $\mathrm{CB}$ (Fig. 6c and e), and this declining salinity trend extends to the center of the CB (Fig. 6e), whereas, salt water moves into the bays through the OCI, resulting in high salinity in the upper arm of the bays (Fig. 6c and e). Without the OCI or CI, the average salinity of the MCBs reduces by about $3.7 \%$ and $1.3 \%$, respectively. This is consistent 
with the findings of Pritchard (1960), as closing any inlet leads to the lower salinity of the MCBs. Collectively, our simulations show that cutting off any inlet results in the huge difference for the hydrodynamics of the nearby cut-off inlet areas.

\subsection{Water Exchange and Salt Flux Simulation under Different Wind Forcing}

Water/salt flux was calculated from Sept. 11, 00:00:00 UTC to Sept. 14, 00:00:00 UTC

(3 days) 2004 with 30-min intervals at the major entrance inlets to quantify bay-ocean exchange, and to investigate the relationship between the export/import of water/salt flux from the bays and the relevant physical forcing. Water exchange and salt flux calculations were made for eighteen separate but similar scenarios (Run 1 to Run 18 in Table 1). Simulated water/salt flux for the first eleven scenarios and Run 18 are shown in Table 4 for both surface and bottom. The water/salt flux oscillates between positive and negative values (in/out) for both inlets, based on wind/tide events. With no winds, tides and river inflow, the total water flux is only $0.71 \mathrm{~m}^{3} / \mathrm{s}$, which is very close to no flow (Table 4).

The evident flux-changing trend for each inlet appears with the augmentation of wind speeds from different directions (Table 4). The outflow at the OCI increases when SW winds become stronger, while the inverse flow pattern occurs at the OCI under the influence of NW winds. The outflow decreases for surface and bottom, which followed by moving-in flux when strongest winds $(15 \mathrm{~m} / \mathrm{s})$ are encountered. Likewise, $\mathrm{SW}$ winds enhance inflow of the CI at stronger wind speeds, while outflow of the CI increases forced by NW winds. The simulated salt flux shares the same flux-changing trend as the 
water flux for each inlet under the same wind forcing, and this suggests that water and salt flux are sensitive to the wind fields.

Surface flux varies more with the wind forcing than bottom flux in terms of water and salt, indicating that surface flux contributes more greatly to the net flux variation (Table 4). This is in agreement with results obtained for calculated water and salt exchange through inlets in Perdido Bay as surface flux makes a greater contribution to the variance of the net flux under the effect of winds (Xia et al., 2011).

The depth-averaged spatial salinity with depth-averaged current velocity caused by NW/SW winds elucidates the importance of wind forcing on the exchange processes. Here, three typical wind speeds, representing weak wind $(3 \mathrm{~m} / \mathrm{s})$, mild wind $(7 \mathrm{~m} / \mathrm{s})$ and strong wind $(15 \mathrm{~m} / \mathrm{s})$, from northwest and southwest were chosen for the study. Highsaline water from the adjacent coastal ocean passes into the bays through the OCI favored by mild/strong NW winds (Fig. 7h and i), raising the salinity of the SB (Fig. 7b and c); meanwhile, low-saline water of the CB is most likely to be transported out of the bays through the CI (Fig. 7m, $\mathrm{n}$ and o). When reaching the strongest wind speeds, low-saline water from the northern portion of the MCBs flows directly to the south (Fig. 7i). The effect of weak NW winds on the spatial salinity with the current velocity vector of the MCBs is subtle (Fig. 7a, g, and m). Ideally constant mild and strong NW winds (blowing from northwest to southeast) initiates the depth-averaged southwestward flow within the study area (Fig. 7b and c), while the current velocity is positively correlated to the wind magnitude as stronger winds result in enhanced current flow (Fig. $7 \mathrm{~g}, \mathrm{~h}, \mathrm{i}, \mathrm{m}, \mathrm{n}$ and o). In 
contrast, SW winds draw salt water into the bays through the CI (Fig. 7p, q and r) to mix with the low-saline water, and leads to high salinity of the MCBs (Fig. 7d, e, and f) and outflow pattern for the OCI (Fig. $7 \mathrm{j}, \mathrm{k}$ and 1). Spatially uniform constant SW winds (blowing from southwest to northeast) reverse the current flow to the northeastward direction (Fig. 7d, e and f); similarly, enhanced current flow is mainly driven by the relatively stronger wind for both inlets (Fig. 7j, k, 1, p, q and r). Alongshore SW winds tend to promote the current velocity more easily than across-bay NW winds (Fig. 7) as wind orientation that aligns with the shape of the bays, particular the shape of the $\mathrm{CB}$ with the largest portion of the surface areas of the MCBs, could easily lead to the specific flow pattern, which is consistent with the study of wind regime on the flow pattern of the Virginia Coast Reserve (Mied et al., 2010).

Another effort to corroborate the flux trend favored by the typical winds is the vertical current velocity profile of transects at the OCI and CI. The water flows out of the OCI when NW winds are weak (Fig. 8a). The onshore current gets stronger with the intensification of NW winds, leading to the flow-in pattern at the OCI (Fig. 8b and c). Small parts of the flow move into the bay through the OCI under the weak SW winds (Fig. 8d). Mild/strong SW winds easily enhance the Ekman flux as the OCI orientation follows a northwest to southeast pattern (Fig. 1e), leading to the outflow pattern of the OCI (Fig. 8e and f). The shallow depth of the OCI $(7 \mathrm{~m})$ compared to the deep ocean with the relative importance of bottom roughness parameter may limit the Ekman flux to the right of the wind direction under the weak SW winds, which supports the study of water transport through the Marsdiep inlet in the western Dutch Wadden Sea (Buijsman and Ridderinkhof, 2007). However, the CI orientation is as from northeast to southwest (Fig. 
1f), and flow could move into the CI when NW winds are weak (Fig. 8g). Similarly, the influence of flux transport is not evident due to the shallow depth of the CI with the higher bottom roughness impacted by weak NW winds. Persistent mild/strong NW winds push more water out of the bay though the CI (Fig. 8h and i). While SW winds push the water into the bay through the CI (Fig. $8 \mathrm{j}, \mathrm{k}$ and 1$)$. The different vertical current velocity behaviors at the inlet transect of the OCI and CI are closely related to the different depth patterns and its steepness at inlet transects. Moreover, the inlet orientation and the favorable wind directions to the Ekman flux play important roles in determining the vertical current velocity profiles at the transect of the OCI and CI. The MCBs gain flux through the OCI and release flux from the CI under NW winds. SW winds tend to promote the landward flux through the CI and seaward flux through the OCI. In the view

of the total flux trend (Table 4), strong NW winds promote more flux out of the bays as NW winds can easily promote flux out of the CI, whereas, under strong SW winds, more flux transport through the CI into the bay occurs due to its wider width and the influence of shore-parallel SW winds (Mied et al., 2010).

The simulation results of water/salt flux for different wind directions verify the description of the physical setting of the MCBs (Krantz et al., 2009), which proves that the orientation and shape of the MCBs, especially the shape of the $\mathrm{CB}$, are important factors leading to this simulated result.

4.3 The Effect of Individual Forcing (Winds and Tides) on Water Exchange and Salt Flux Dynamics 
Previous studies have investigated the effect of winds or tides on exchange processes in various study areas (Kitheka, 1997; Wong and Valle-Levinson, 2002; Narváez and ValleLevinson, 2008; MacCready et al., 2009; Malhadas et al., 2010; Xia et al., 2011; Yang and Wang, 2013).

The water and salt flux simulations discussed in Section 4.2 show the variability under different wind conditions. To investigate the effect of each physical forcing on exchange processes of the MCBs, six additional numerical experiments, driven only by the typical wind forcing (Run 12 to Run 17 in Table 1), and one scenario (Run 18 in Table 1) driven only by the tidal forcing in the absence of wind fields, were conducted using this validated model.

With only wind forcing, NW winds cause flux inward through the OCI and outward through the CI whilst SW winds enhance inflow through the CI and outward flux through the OCI (Fig. 9a, b, c and d). Wind forcing could play a dominant role in the water exchange and salt flux for both inlets forced by higher wind speeds (Fig. 9a, b, c, d, e and f), especially leaving the tidal flux term smaller relative to the No-wind case under SW winds. The tidal flux term stays more or less the same as the No-wind case under NW winds.

Another way to verify the influence of wind forcing is to explore the percentage of wind forcing on exchange processes. Although water/salt flux is not simply linear-combined by the effect of winds and tides, the percentage of only wind forcing over both winds and 
tides may still illustrate its importance on exchange processes. Wind forcing accounts for a larger portion of water/salt flux in response to the larger wind speeds (Fig. 9g and $\mathrm{h}$ ), especially under SW winds with $\sim 90 \%$. This is consistent with the study of wind regime on the flow pattern of the Virginia Coast Reserve (Mied et al., 2010) as shore-parallel winds can promote the flow pattern more easily than across-bay winds. Consequently, tidal forcing is the major driver of water exchange and salt flux for both inlets at weak wind speeds. The effect of tides on flux dynamics weakens with the augmentation of wind speeds.

\section{Conclusion}

A 3D unstructured-grid hydrodynamic model--FVCOM was used to investigate the flux exchange through inlets between the MCBs and their adjacent coastal ocean. With the detailed horizontal grid resolution and sufficient vertical sigma levels for the overall shallow depth of the MCBs, the model showed its capability to capture the complicated geometry and irregular shorelines, and produced the hydrodynamic characteristics within the study area. The sensitivity tests on water elevation, current velocity and salinity simulation without any inlet, and the flux dynamics sensitivity to major external forcing, including winds and tides, were examined. The major conclusions are as follows:

(1) Water elevation, current velocity and salinity are sensitive to different numerical experiments with closing either inlet. Without any inlet, it greatly influences the hydrodynamic parameters nearby the closed inlet areas, as the interaction between the 
bays and the coastal ocean is cut off. The effect of closing any inlet on the hydrodynamic parameters becomes weaker with greater distance from inlet areas.

(2) Water exchange and salt flux were linked by using quantitative analysis. The results reveal that major external forcing (winds and tides) significantly influence water exchange and subsequent salt flux. Along-shore SW winds cause landward flux through the CI and seaward flux through the OCI. However, the reverse flow pattern through inlets occurs impacted by across-bay NW winds, with outflow through the CI and inflow through the OCI. Alongshore SW winds can promote the flow pattern of the MCBs more easily than across-bay NW winds, which are caused by the influence of wind orientation aligning with the shape of the bays, particular the shape of the CB.

(3) When winds and tides were studied independently, it was found that winds play a dominant role in the water exchange and salt flux through both inlets at higher wind speeds. By contrast, tides are the major forcing on the flux dynamics at both inlets under weak wind speeds, and its effect gradually weakens at higher wind speeds. In fact, winds and tides are both important factors contributing to the exchange processes of the MCBs, and neither of them can be ignored. Bay-shelf water and salt flux through the two inlets is crucial to understanding the dynamics of the MCBs.

The basic understanding of flux dynamics of the MCBs provides an example of the roles of winds and tides in determining the exchange processes in the coastal water bodies, and they are essential to the future relevant oceanographic study in the MCBs. However, the 
related observational data are still in scarcity. The state-of-the-art coastal ocean observing systems (e.g., Liu et al., 2015) are needed for this region in the future. Moreover, more studies focusing on the hydrodynamics of the MCBs, such as the effect of adding an inlet in the washover event during storms, and the role of winds and tides contributing to the spatial exchange process within the bays, are needed for the future work. Similarly, this model method and work are useful to developed models for other estuaries, shallow bay and coastal systems.

\section{Acknowledgments}

Research was carried on Yellowstone of Computational \& Information Systems Lab (CISL). X. Kang was partially supported by a Department Teaching Assistantship. This research was partially supported by Maryland Sea Grant, National Park Services North Atlantic Coast Cooperative Ecosystem Study Unit and NSF CREST Center. Thanks for

the comments of three reviewers and helps from Dr. Neil K. Ganju of USGS to get the observed current velocity data. Dr. Harry V. Wang from VIMS was appreciated to share their Maryland Coastal Bay model inputs with us. 


\section{Reference}

Arega, F., Armstrong, S., Badr, A.W., 2008. Modeling of residence time in the East Scott Creek Estuary, South Carolina, USA. J. Hydro. Environ. Res. 2 (2), 99-108. http://dx.doi.org/10.1016/j.jher.2008.07.003

Bao, X., Yan, J., Sun, W., 2000. A three-dimensional tidal model in boundary-fitted curvilinear grids. Estuar. Coast. Shelf Sci. 50 (6), 775-788.

http://dx.doi.org/10.1006/ecss.2000.0605

Bilgili, A., Proehl, J.A., Lynch, D.R., Smith, K.W., Swift, M.R., 2005. Estuary/ocean exchange and tidal mixing in a Gulf of Maine Estuary: A Lagrangian modeling study. Estuar. Coast. Shelf Sci. 65 (4), 607-624. http://dx.doi.org/10.1016/j.ecss.2005.06.027

Boynton, W.R., Murray, L., Hagy, J.D., Stokes, C., Kemp, W.M., 1996. A comparative analysis of eutrophication patterns in a temperate coastal lagoon. Estuaries 19 (2), 408421. http://dx.doi.org/10.2307/1352459

Buijsman, M.C., Ridderinkhof, H., 2007. Long-term ferry-ADCP observations of tidal currents in the Marsdiep inlet. J. Sea Res. 57 (4), 237-256.

http://dx.doi.org/10.1016/j.seares.2006.11.004

Casares-Salazar, R., Mariño-Tapia, I., 2016. Influence of the remote forcing and local winds on the barotropic hydrodynamics of an elongated coastal lagoon. J. Coastal Res. 32 
(1), 116-130. http://dx.doi.org/10.2112/JCOASTRES-D-14-00146.1

Chen, C., Beardsley, R.C., Cowles, G., 2006. An unstructured Grid, Finite-Volume Coastal Ocean Model (FVCOM) System. Oceanography 19 (1), 78-89. http://dx.doi.org/10.5670/oceanog.2006.92

Chen, C., Huang, H., Beardsley, R.C., Xu, Q., Limeburner, R., Cowles, G.W., Sun, Y., Qi, J., Lin, H., 2011. Tidal dynamics in the Gulf of Maine and New England Shelf: An application of FVCOM. J. Geophys. Res. 116, C12010. http://dx.doi.org/10.1029/2011JC007054

Chen, C., Xue, P., Ding, P., Beardsley, R.C., Xu. Q., Mao, X., Gao, G., Qi, J., Li, C., Lin, H., Cowles, G., Shi, M., 2008. Physical mechanisms for the offshore detachment of the Changjiang Diluted Water in the East China Sea. J. Geophys. Res. 113, C02002. http://dx.doi.org/10.1029/2006JC003994

Cianelli, D., Falco, P., Iermano, I., Mozzillo, P., Uttieri, M., Buonocore, B., Zambardino, G., Zambianchi, E., 2015. Inshore/offshore water exchange in the Gulf of Naples. J. Mar. Sys. 145, 37-52. http://dx.doi.org/10.1016/j.jmarsys.2015.01.002

Dettmann, E.H., 2001. Effect of water residence time on annual export and denitrification of nitrogen in estuaries: A model analysis. Estuaries 24 (4), 481-490. http://dx.doi.org/10.2307/1353250 
Dufresne, C., Duffa, C., Rey, V., 2014. Wind-forced circulation model and water exchanges through the channel in the Bay of Toulon. Ocean Dynam. 64 (2), 209-224. http://dx.doi.org/10.1007/s10236-013-0676-3

Egbert, G.D., Erofeeva, S.Y., 2002. Efficient inverse modeling of barotropic ocean tides. J. Atmos. Oceanic Technol. 19, 183-204. http://dx.doi.org/10.1175/1520-0426(2002)019<0183:EIMOBO>2.0.CO;2

Galperin, B., Kantha, L.H., Hassid, S., Rosati, A., 1988. A quasi-equilibrium turbulent energy model for geophysical flows. J. Atmos. Sci. 45 (1), 55-62. http://dx.doi.org/10.1175/1520-0469(1988)045<0055:AQETEM>2.0.CO;2

Gustafsson, B.G., 2000. Time-dependent modeling of the Baltic entrance area. 2. Water and salt exchange of the Baltic Sea. Estuaries 23 (2), 253-266. http://dx.doi.org/10.2307/1352831

Herrling, C., Winter, C., 2015. Tidally- and wind-driven residual circulation at the multiple-inlet system East Frisian Wadden Sea. Cont. Shelf Res. 106, 45-59. http://dx.doi.org/10.1016/j.csr.2015.06.001 
Hetzel, Y., Pattiaratchi, C., Lowe, R., Hofmeister, R., 2015. Wind and tidal mixing controls on stratification and dense water outflows in a large hypersaline bay. J. Geophys. Res. Oceans. 120, 6034-6056. http://dx.doi.org/10.1002/2015JC010733

Jesien, R.V., et al., 2009. Diversity of Life in the Coastal Bays. In: Dennison W.C., Thomas, J.E., Cain, C.J., Carruthers, T.J.B., Hall, M.R., Jesien R.V., Wazniak, C.E., Wilson, D.E. (Eds.), Shifting Sands: Environmental and cultural change in Maryland's Coastal Bays. IAN Press at University of Maryland Center for Environmental Science, Cambridge, MD, pp. 293-344.

Jiang, L., Xia, M., 2016. Dynamics of the Chesapeake Bay outflow plume: Realistic plume simulation and its seasonal and interannual variability. J. Geophys. Res. Oceans. 121, 1424-1445. http://dx.doi.org/10.1002/2015JC011191

Kim, C., Park, K., 2012. A modeling study of water and salt exchange for a micro-tidal, stratified northern Gulf of Mexico estuary. J. Mar. Sys. 96-97, 103-115. http://dx.doi.org/10.1016/j.jmarsys.2012.02.008

Kimmerer, W.J., Gross, E.S., MacWilliams, M.L., 2014. Tidal migration and retention of estuarine zooplankton investigated using a particle-tracking model. Limnol. Oceanogra. 59 (3), 901-916. http://dx.doi.org/10.4319/1o.2014.59.3.0901

Kitheka, J.U., 1997. Coastal tidally-driven circulation and the role of water exchange in 
the linkage between tropical coastal ecosystems. Estuar. Coast. Shelf Sci. 45 (2), 177187. http://dx.doi.org/10.1006/ecss.1996.0189

Kraines, S.B., Suzuki, A., Yanagi, T., Isobe, M., Guo, X., Komiyama, H., 1999. Rapid water exchange between the lagoon and the open ocean at Majuro Atoll due to wind, waves and tide. J. Geophys. Res. 104, C7, 15635-15653.

http://dx.doi.org/10.1029/1999JC900065

Krantz, D.E., Schupp, C.A., Spaur, C.C., Thomas, J.E., Wells, D.V., 2009. Dynamic systems at the land-sea interface. In: Dennison W.C., Thomas, J.E., Cain, C.J., Carruthers, T.J.B., Hall, M.R., Jesien R.V., Wazniak, C.E., Wilson, D.E. (Eds.), Shifting Sands: Environmental and Cultural Change in Maryland's Coastal Bays. IAN Press at University of Maryland Center for Environmental Science, Cambridge, MD, pp. 211-248.

Lemagie, E.P., Lerczak, J.A., 2015. A comparison of bulk estuarine turnover timescales to particle tracking timescales using a model of the Yaquina Bay estuary. Estuaries Coasts. 38 (5), 1797-1814. http://dx.doi.org/10.1007/s12237-014-9915-1

Liu, Y., Kerkering, H., Weisberg, R.H., 2015. Coastal Ocean Observing Systems. Elsevier, London, UK, $461 \mathrm{pp}$. 
Liu, Y., MacCready, P., Hickey, B.M., Dever, E.P., Kosro, P.M., Banas, N.S., 2009.

Evaluation of a coastal ocean circulation model for the Columbia River plume in summer 2004. J. Geophys. Res. 114, C00B04. http://dx.doi.org/10.1029/2008JC004929

Liu, Z., Wei, H., Liu, G., Zhang, J., 2004. Simulation of water exchange in Jiaozhou Bay by average residence time approach. Estuar. Coast. Shelf Sci. 61 (1), 25-35. http://dx.doi.org/10.1016/j.ecss.2004.04.009

Love, J.W., Chigbu, P., May, E.B., 2009. Environmental variability affects distributions of coastal fish species (Maryland). Northeast. Nat. 16 (2), 255-268. http://dx.doi.org/10.1656/045.016.0207

Lung, W.S., 1994. Water quality modeling of the St. Martin River, Assawoman and Isle of Wight Bays. Maryland Department of the Environment, pp. 156.

MacCready, P., Banas, N.S., Hickey, B.M., Dever, E.P., Liu, Y., 2009. A model study of tide- and wind-induced mixing in the Columbia River Estuary and plume. Cont. Shelf Res. 29 (1), 278-291. http://dx.doi.org/10.1016/j.csr.2008.03.015

Malhadas, M.S., Neves, R.J., Leitão, P.C., Silva, A., 2010. Influence of tide and waves on water renewal in Óbidos Lagoon, Portugal. Ocean Dynam. 60 (1), 41-55. http://dx.doi.org/10.1007/s10236-009-0240-3 
Manheim, F., 2002. Progress in delineating submarine ground-water discharge in Delmarva Coastal Bays. http://soundwaves.usgs.gov/2002/06/research.html

Mellor, G.L., Yamada, T., 1982. Development of a turbulence closure model for geophysical fluid problems. Rev. Geophys. 20 (4), 851-875.

http://dx.doi.org/10.1029/RG020i004p00851

Mied, R.P., Schulz, W.J., Handler, R.A., Snow, C.M., Fusina, R.A., Porter, J.H., 2010. Remote and local forcing of a coastal lagoon: The Virginia Coast Reserve. Cont. Shelf Res. 30 (20), 2057-2066. http://dx.doi.org/10.1016/j.csr.2010.10.005

Narváez, D.A., Valle-Levinson, A., 2008. Transverse structure of wind-driven flow at the entrance to an estuary: Nansemond River. J. Geophys. Res. 113, C09004. http://dx.doi.org/10.1029/2008JC004770

Niu, Q., Xia, M., Rutherford, E.S., Mason, D.M., Anderson, E.J., Schwab, D.J., 2015. Investigation of interbasin exchange and interannual variability in Lake Erie using an unstructured-grid hydrodynamic model. J. Geophys. Res. Oceans. 120, 2212-2232. http://dx.doi.org/10.1002/2014JC010457

Pawlowicz, R., Beardsley, B., Lentz, S., 2002. Classical tidal harmonic analysis including error estimates in MATLAB using T_TIDE. Comput. Geosci. 28 (8), 929-937. http://dx.doi.org/10.1016/S0098-3004(02)00013-4 
Pfeiffer-Herbert, A.S., Kincaid, C.R., Bergondo, D.L., Pockalny, R.A., 2015. Dynamics of wind-driven estuarine-shelf exchange in the Narragansett Bay estuary. Cont. Shelf Res. 105, 42-59. http://dx.doi.org/10.1016/j.csr.2015.06.003

Pritchard, D.W., 1960. Salt balance and exchange rate for Chincoteague Bay. Chesapeake Science 1 (1), 48-57. http://dx.doi.org/10.2307/1350536

Safak, I., Wiberg, P.L., Richardson, D.L., Kurum, M.O., 2015. Controls on residence time and exchange in a system of shallow coastal bays. Cont. Shelf Res. 97, 7-20. http://dx.doi.org/10.1016/j.csr.2015.01.009

Smagorinsky, J., 1963. General circulation experiments with the primitive equations. 1: The basic experiment. Mon. Weather Rev. 91 (3), 99-164. http://dx.doi.org/10.1175/1520-0493(1963)091<0099:GCEWTP>2.3.CO;2

Stigebrandt, A., 1983. A model for the exchange of water and salt between the Baltic and the Skagerrak. J. Phys. Oceanogr. 13, 411-427. http://dx.doi.org/10.1175/1520-0485(1983)013<0411:AMFTEO>2.0.CO;2

Valle-Levinson, A., Klinck, J.M., Wheless, G.H., 1996. Inflows/outflows at the transition between a coastal plain estuary and the coastal ocean. Cont. Shelf Res. 16 (14), 18191847. http://dx.doi.org/10.1016/0278-4343(96)00016-7 
Valle-Levinson, A., Lwiza, K.M.M., 1995. The effects of channels and shoals on exchange between the Chesapeake Bay and the adjacent ocean. J. Geophys. Res. 100, C9, 18551-18563. http://dx.doi.org/10.1029/95JC01936

Valle-Levinson, A., Wong, K.C., Bosley, K.T., 2001. Observations of the wind-induced exchange at the entrance to Chesapeake Bay. J. Mar. Res. 59 (3), 391-416. http://dx.doi.org/10.1357/002224001762842253

Wang, H., Wang, Z., Loftis, J.D., Teng, Y.C., 2013. Hydrodynamic and water quality modeling and TMDL development for Maryland's coastal Bays system. Final report submitted to Maryland Department of the Environment, TMDL Technical Development Program.

Wang, J., Shen, Y., Guo, Y., 2010. Seasonal circulation and influence factors of the Bohai Sea: a numerical study based on Lagrangian particle tracking method. Ocean Dynam. 60 (6), 1581-1596. http://dx.doi.org/10.1007/s10236-010-0346-7

Wazniak, C., Wells, D., Hall, M., 2005. The Maryland Coastal Bays ecosystem. In: Wazniak, C.E., Hall, M.R. (Eds.), Maryland's Coastal Bays: Ecosystem Health Assessment 2004. Annapolis, MD, Maryland Department of Natural Resources, Document number: DNR-12-1202-0009, pp. 1-9-1-20. 
Weisberg, R.H., Zheng, L., 2006. Circulation of Tampa Bay driven by buoyancy, tides, and winds, as simulated using a finite volume coastal ocean model. J. Geophys. Res. 111, C01005. http://dx.doi.org/10.1029/2005JC003067

Wells, D.V., VanRyswick, S., Ortt, R.A., Jr., Conkwright, R.D., Offerman, K.A., 2004. Hydrodynamic modeling in the southern Coastal Bays: Water level monitoring, September 7-October 12, 2004. Report submitted to Tidewater Ecosystem Assessment, Resource Assessment Service, Maryland Department of Natural Resources.

Whitney, M.M., Garvine, R.W., 2006. Simulating the Delaware Bay buoyant outflow: Comparison with observations. J. Phys. Oceanogr. 36, 3-21. http://dx.doi.org/10.1175/JPO2805.1

Wong, K.C., Valle-Levinson, A., 2002. On the relative importance of the remote and local wind effects on the subtidal exchange at the entrance to the Chesapeake Bay. J. Mar. Res. 60 (3), 477-498. http://dx.doi.org/10.1357/002224002762231188

Xia, M., Xie, L., Pietrafesa, L.J., Whitney, M.M., 2011. The ideal response of a Gulf of Mexico estuary plume to wind forcing: Its connection with salt flux and a Lagrangian view. J. Geophys. Res. 116, C08035. http://dx.doi.org/10.1029/2010JC006689 
Xue, P., Chen, C., Ding, P., Beardsley, R.C., Lin, H., Ge, J., Kong, Y., 2009. Saltwater intrusion into the Changiiang River: A model-guided mechanism study. J. Geophys. Res. 114, C02006. http://dx.doi.org/10.1029/2008JC004831

Yang, Z., Wang, T., 2013. Tidal residual eddies and their effect on water exchange in Puget Sound. Ocean Dynam. 63 (8), 995-1009.

http://dx.doi.org/10.1007/s10236-013-0635-z

Zheng, L., Chen, C., Liu, H., 2003. A modeling study of the Satilla River estuary, Georgia, I: Flooding-drying process and water exchange over the salt marsh-estuary-shelf complex. Estuaries 26 (3), 651-669. http://dx.doi.org/10.1007/BF02711977

Zhu, J., Weisberg, R.H., Zheng, L., Qi, H., 2015. On the salt balance of Tampa Bay. Cont. Shelf Res. 107, 115-131. http://dx.doi.org/10.1016/j.csr.2015.07.001 


\section{List of Figures and Tables}

Fig. 1. (a) Locations of the MCBs (Krantz et al., 2009); (b) Bathymetry of the MCBs including the locations of observed stations. Black triangles: water elevation gauges; red triangles: observed salinity stations; magenta squares: river inputs stations; (c) Enlarged map for the green box in (b) with observed stations near the OCI. Orange circle: observed current velocity station; (d) Grid mesh of the simulation domain with boxes illustrating the inlet areas; (e) Enlarged map for the red box in (d) for the OCI; (f) Enlarged map for the orange box in (d) for the CI; grids around inlet areas without the OCI (g) and without the CI (h).

Fig. 2. Wind rose diagrams for the MCBs during (a) summer (June to August), and (b) winter (December to February) of 2003 to 2013. Data Source: MesoWest Data.

Fig. 3. Water elevation time series with different bottom roughness parameters at: (a) Ocean City Inlet, (b) Snug Harbor, (c) South Point, (d) Public Landing and (e) Harbor of Refuge; Model-validated (blue dash) versus observed (red solid) water elevation time series at: (f) Ocean City Inlet, (g) Snug Harbor, (h) South Point, (i) Public Landing and (j) Harbor of Refuge; Water elevation time series and correlation coefficients with $p$ values for different sensitivity tests: (k) Ocean City Inlet; (1) Snug Harbor; (m) South Point; (n) Public Landing; (o) Harbor of Refuge.

Fig. 4. (a) Along-channel, depth-averaged, current velocity in the Isle of Wight Bay Channel time series and correlation coefficients with $p$ values for different sensitivity tests; (b) Model-validated versus observed current velocity with corresponding statistics values. The blue line stands for the perfect fit between the modeled and observed values, and the black dash line represents the 1:1 line. Positive/negative values stand for northward/southward current velocity.

Fig. 5. Wind fields with their salinity time series at observed salinity stations: (a), (f) S1: MD-DNR XDN4312; (b), (g) S2: MD-DNR TUV0011; (c), (h) S3: MD-DNR XDN2438; (d), (i) S4: MD-DNR XCM4878; (e), (j) S5: MD-DNR XBM1301.

Fig. 6. Depth-averaged spatial salinity of the MCBs from Sept. 2, 00:00:00 UTC to Sept. 17, 24:00:00 UTC 2004 from (a) Validation, (b) Without the OCI; (c) Without the CI; (d) the difference between Validation and Without the OCI (b-a); (e) the difference between Validation and Without the CI (c-a). Grey areas stand for the mainland; white areas stand for the adjacent coastal ocean.

Fig. 7. Simulated, depth-averaged, spatial salinity exhibition of the MCBs excited by NW and SW winds at: (a), (d) $3 \mathrm{~m} / \mathrm{s}$; (b), (e) $7 \mathrm{~m} / \mathrm{s}$; (c), (f) $15 \mathrm{~m} / \mathrm{s}$ with its depth-averaged spatial current velocity within the bays, respectively; depth-averaged, spatial salinity exhibition of the OCI with depth-averaged current velocity vectors excited by NW and SW winds at: (g), (j) $3 \mathrm{~m} / \mathrm{s}$; (h), (k) $7 \mathrm{~m} / \mathrm{s}$; (i), (l) $15 \mathrm{~m} / \mathrm{s}$, respectively; depth-averaged, spatial salinity exhibition of the CI with depth-averaged current velocity vectors excited 
by NW and SW winds at: (m), (p) 3m/s; (n), (q) 7m/s; (o), (r) $15 \mathrm{~m} / \mathrm{s}$, respectively. Grey areas stand for the mainland; white areas stand for the adjacent coastal ocean.

Fig. 8. Contours of current velocity at the OCI and CI transects with the interval of 0.05 and $0.1 \mathrm{~m} / \mathrm{s}$ excited by NW winds at: (a), (g) $3 \mathrm{~m} / \mathrm{s}$; (b), (h) $7 \mathrm{~m} / \mathrm{s}$; (c), (i) $15 \mathrm{~m} / \mathrm{s}$; and excited by SW winds at: (d), (j) $3 \mathrm{~m} / \mathrm{s}$; (e), (k) $7 \mathrm{~m} / \mathrm{s}$; (f), (l) $15 \mathrm{~m} / \mathrm{s}$, respectively. Positive/negative signals indicate onshore/offshore movement.

Fig. 9. Calculated water flux at (a) the $\mathrm{OCI}$ and (c) the CI; calculated salt flux across (b) the OCI and (d) the CI; its corresponding net water flux (e) and net salt flux (f) under different physical forcing. Net water flux and net salt flux is the sum of flow and salt for each inlet. Positive/negative signals indicate flow move into/out of the bays. The percentage of winds on water/salt flux at (g) the OCI and (h) the CI, respectively, under different physical forcing.

Table 1 Model experiments.

Table 2 Corresponding statistics of different sensitivity tests on bottom roughness parameters at observed water elevation stations in the MCBs.

Table 3 Attenuations and time lags for observed and simulated water levels at diurnal frequencies.

Table 4 Water flux and salt flux result for different experiments. 

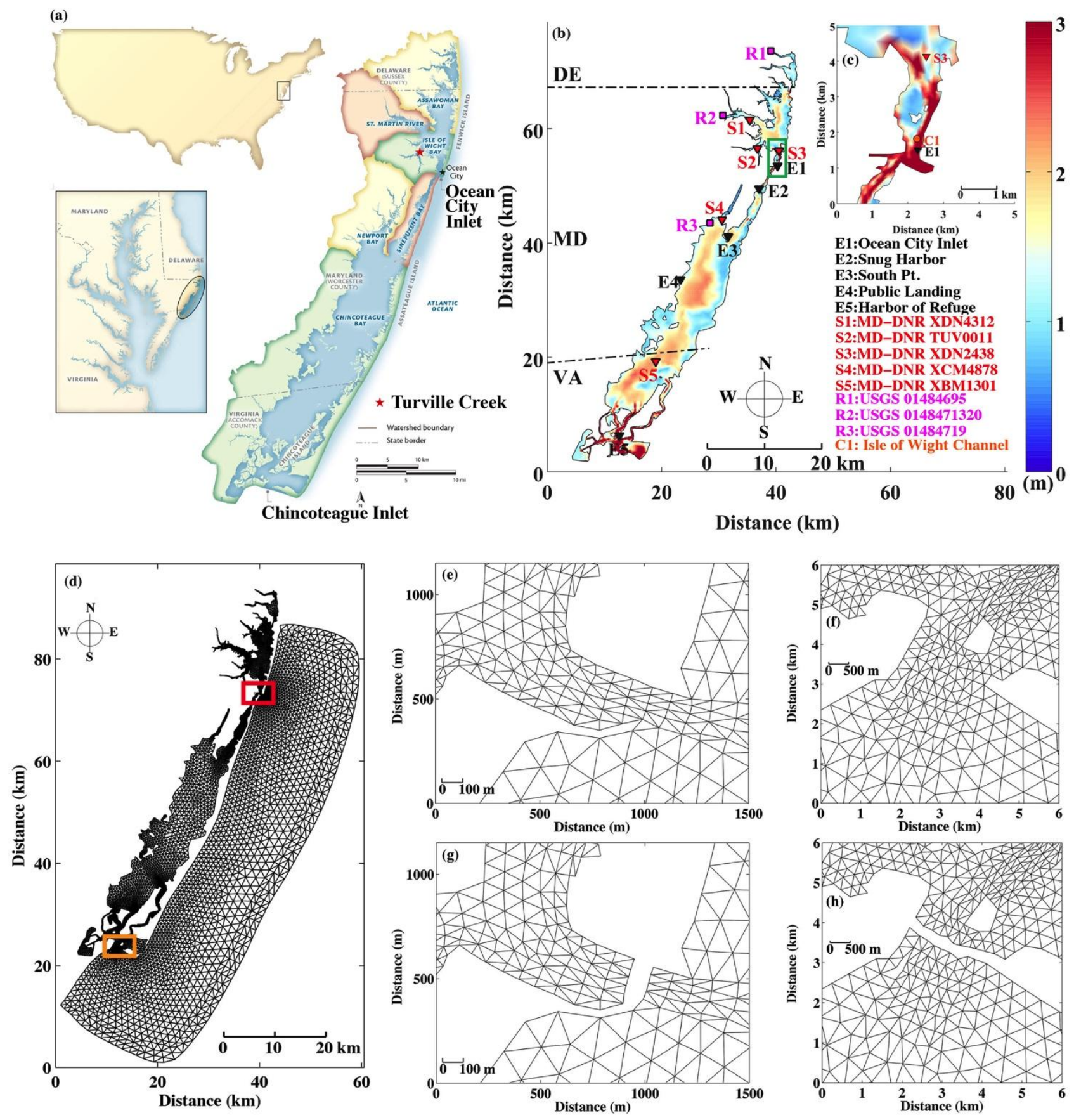

Fig. 1. (a) Locations of the MCBs (Krantz et al., 2009); (b) Bathymetry of the MCBs including the locations of observed stations. Black triangles: water elevation gauges; red triangles: observed salinity stations; magenta squares: river inputs stations; (c) Enlarged map for the green box in (b) with observed stations near the OCI. Orange circle: observed current velocity station; (d) Grid mesh of the simulation domain with boxes illustrating the inlet areas; (e) Enlarged map for the red box in (d) for the OCI; (f) Enlarged map for the orange box in (d) for the CI; grids around inlet areas without the OCI (g) and without the CI (h). 

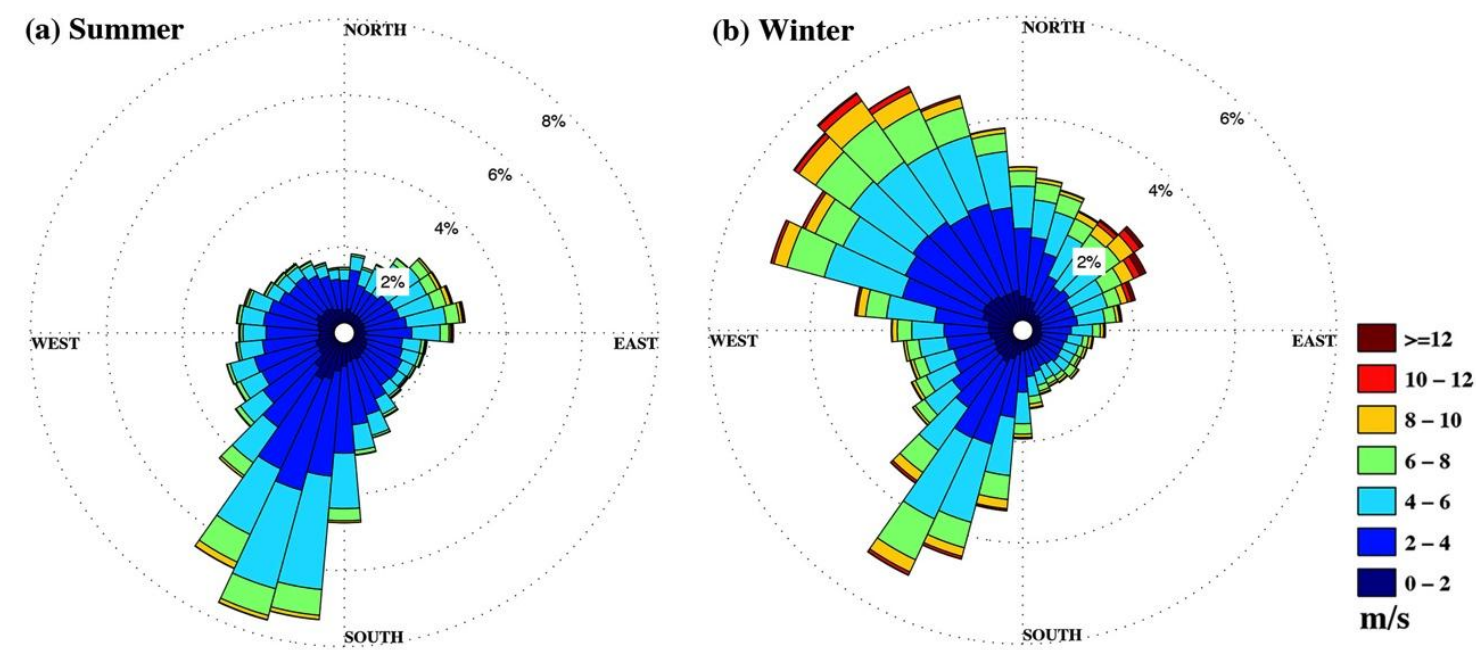

Fig. 2. Wind rose diagrams for the MCBs during (a) summer (June to August), and (b) winter (December to February) of 2003 to 2013. Data Source: MesoWest Data. 


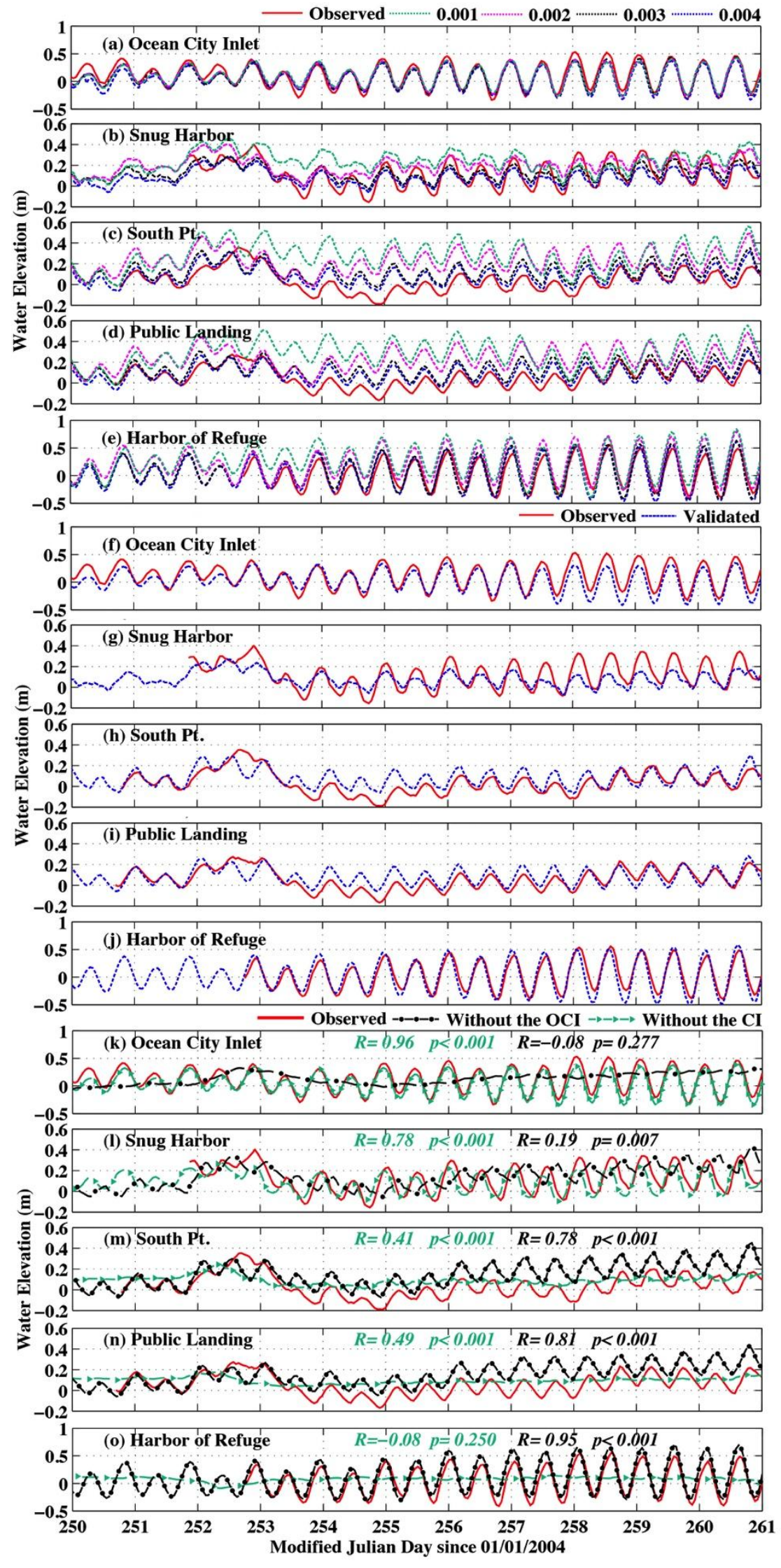


Fig. 3. Water elevation time series with different bottom roughness parameters at: (a) Ocean City Inlet, (b) Snug Harbor, (c) South Point, (d) Public Landing and (e) Harbor of Refuge; Model-validated (blue dash) versus observed (red solid) water elevation time series at: (f) Ocean City Inlet, (g) Snug Harbor, (h) South Point, (i) Public Landing and (j) Harbor of Refuge; Water elevation time series and correlation coefficients with $p$ values for different sensitivity tests: (k) Ocean City Inlet; (l) Snug Harbor; (m) South Point; (n) Public Landing; (o) Harbor of Refuge.
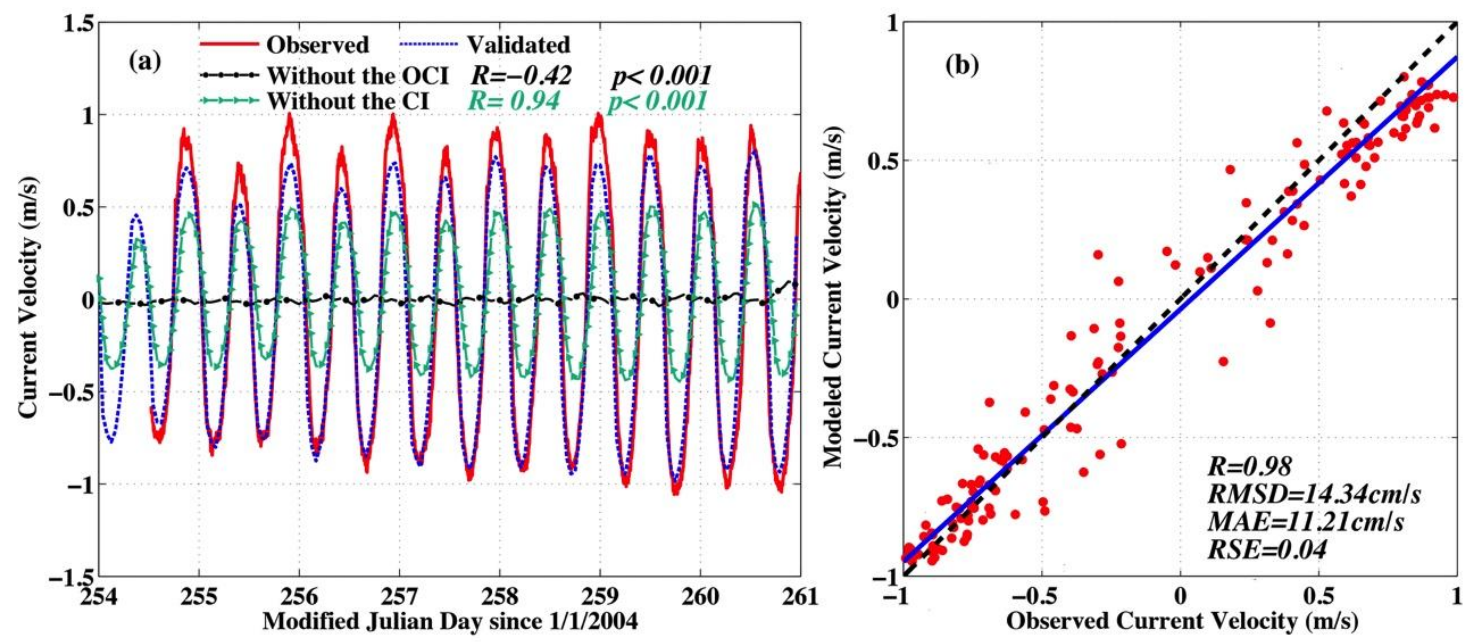

Fig. 4. (a) Along-channel, depth-averaged, current velocity in the Isle of Wight Bay Channel time series and correlation coefficients with $p$ values for different sensitivity tests; (b) Model-validated versus observed current velocity with corresponding statistics values. The blue line stands for the perfect fit between the modeled and observed values, and the black dash line represents the 1:1 line. Positive/negative values stand for northward/southward current velocity. 

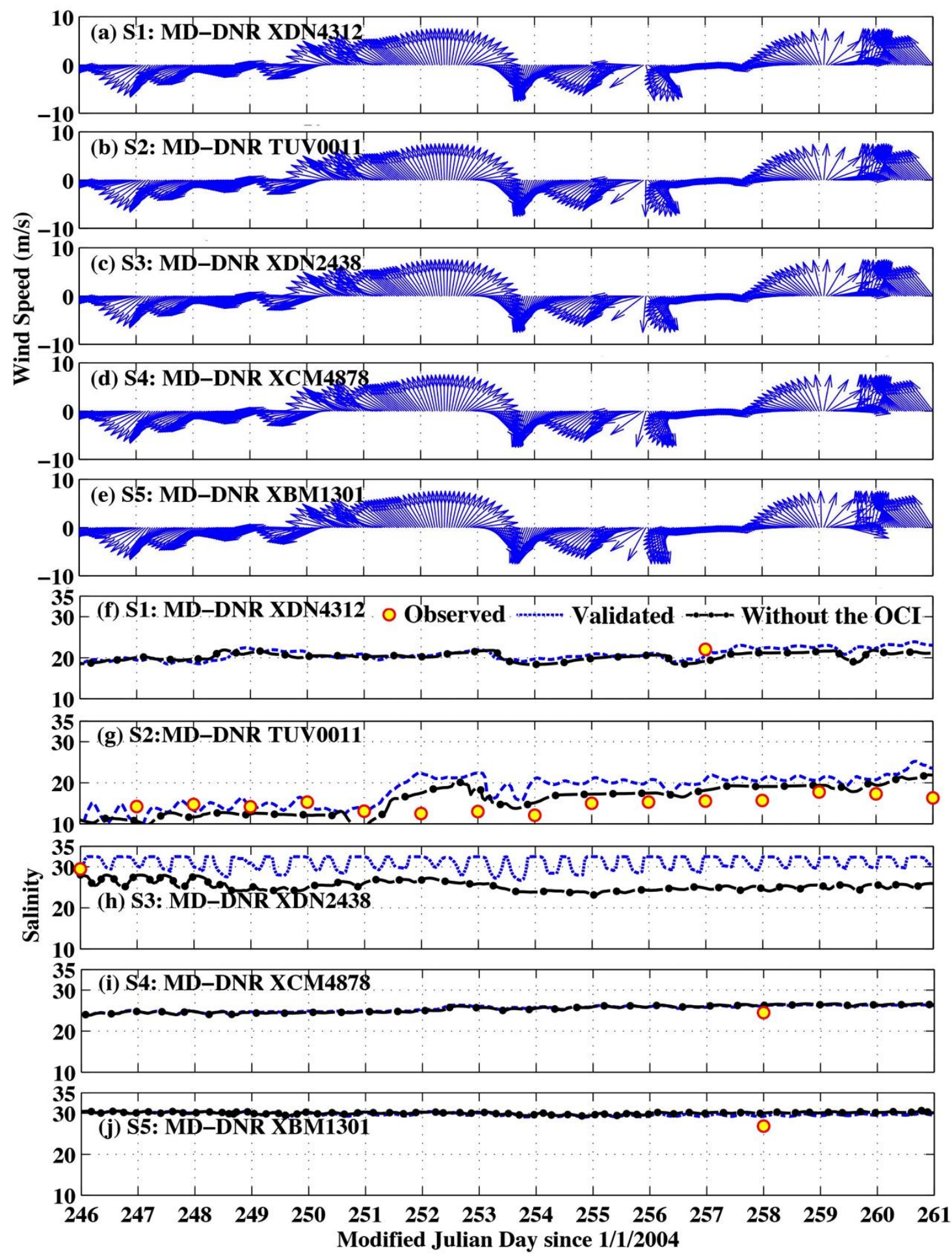

Fig. 5. Wind fields with their salinity time series at observed salinity stations: (a), (f) S1: MD-DNR XDN4312; (b), (g) S2: MD-DNR TUV0011; (c), (h) S3: MD-DNR XDN2438; (d), (i) S4: MD-DNR XCM4878; (e), (j) S5: MD-DNR XBM1301. 

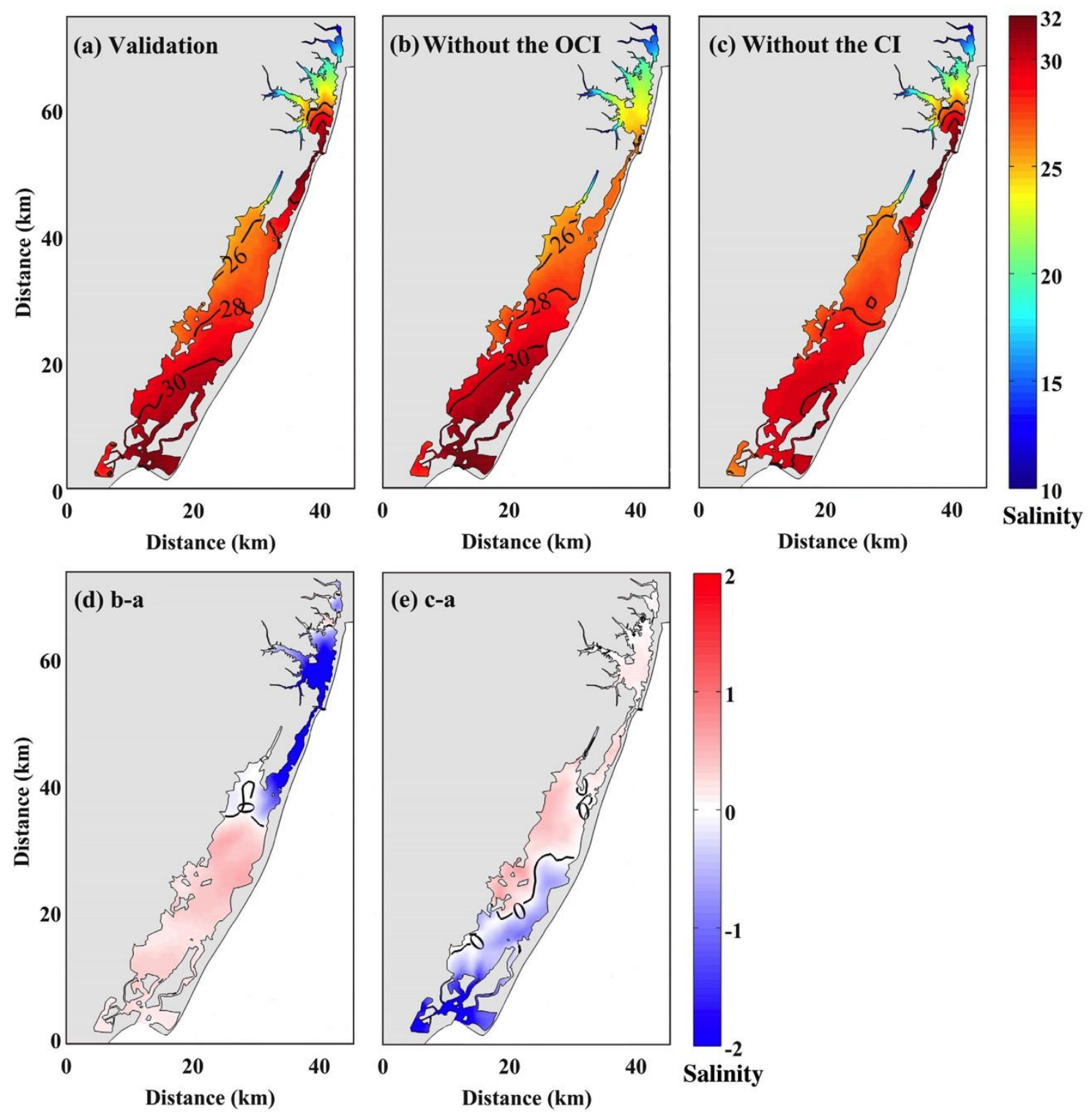

Fig. 6. Depth-averaged spatial salinity of the MCBs from Sept. 2, 00:00:00 UTC to Sept. 17, 24:00:00 UTC 2004 from (a) Validation, (b) Without the OCI; (c) Without the CI; (d) the difference between Validation and Without the OCI (b-a); (e) the difference between Validation and Without the CI (c-a). Grey areas stand for the mainland; white areas stand for the adjacent coastal ocean. 

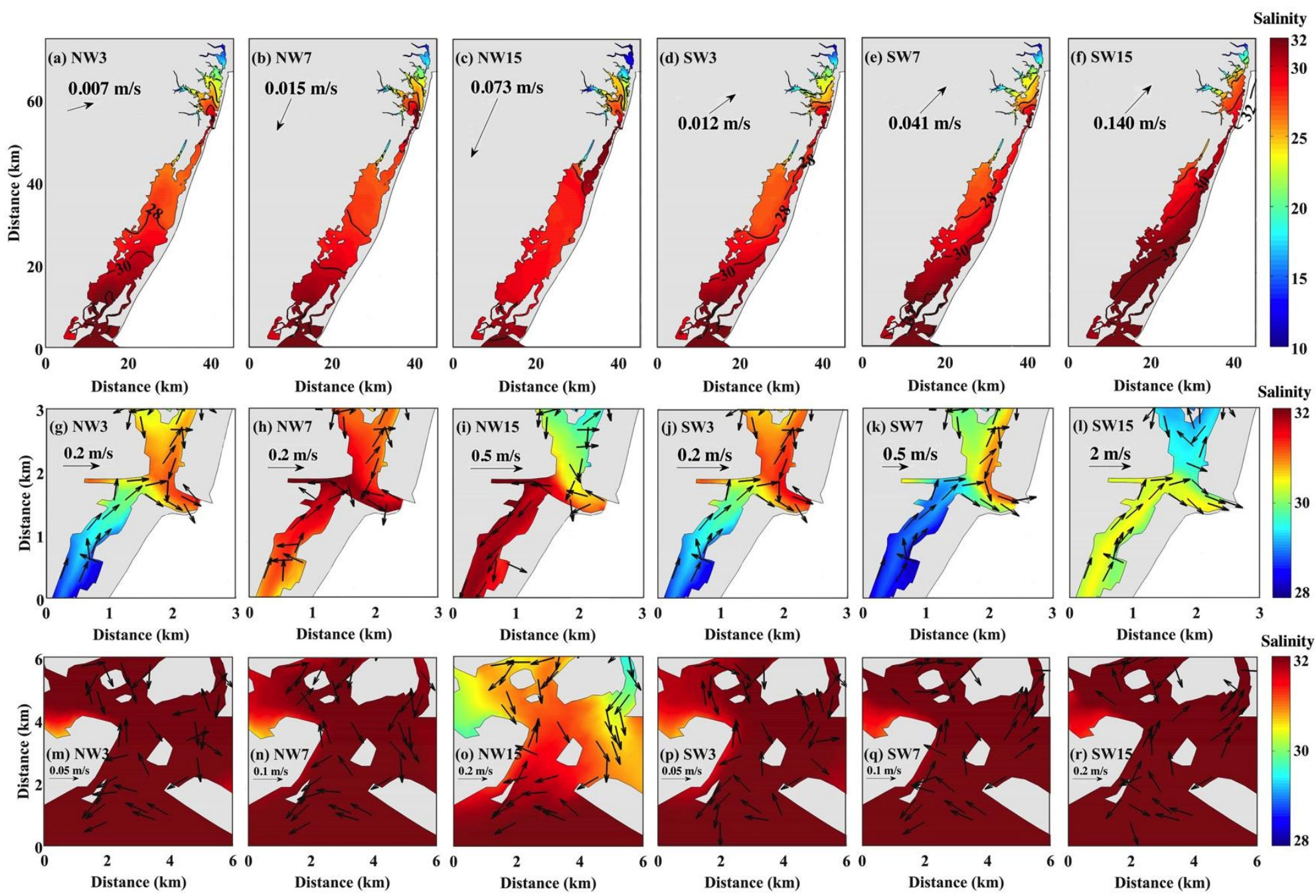

Fig. 7. Simulated, depth-averaged, spatial salinity exhibition of the MCBs excited by NW and SW winds at: (a), (d) $3 \mathrm{~m} / \mathrm{s}$; (b), (e) $7 \mathrm{~m} / \mathrm{s}$; (c), (f) $15 \mathrm{~m} / \mathrm{s}$ with its depth-averaged spatial current velocity within the bays, respectively; depth-averaged, spatial salinity exhibition of the OCI with depth-averaged current velocity vectors excited by NW and SW winds at: (g), (j) $3 \mathrm{~m} / \mathrm{s}$; (h), (k) $7 \mathrm{~m} / \mathrm{s}$; (i), (l) $15 \mathrm{~m} / \mathrm{s}$, respectively; depth-averaged, spatial salinity exhibition of the CI with depth-averaged current velocity vectors excited by NW and SW winds at: (m), (p) $3 \mathrm{~m} / \mathrm{s}$; (n), (q) $7 \mathrm{~m} / \mathrm{s}$; (o), (r) $15 \mathrm{~m} / \mathrm{s}$, respectively. Grey areas stand for the mainland; white areas stand for the adjacent coastal ocean. 

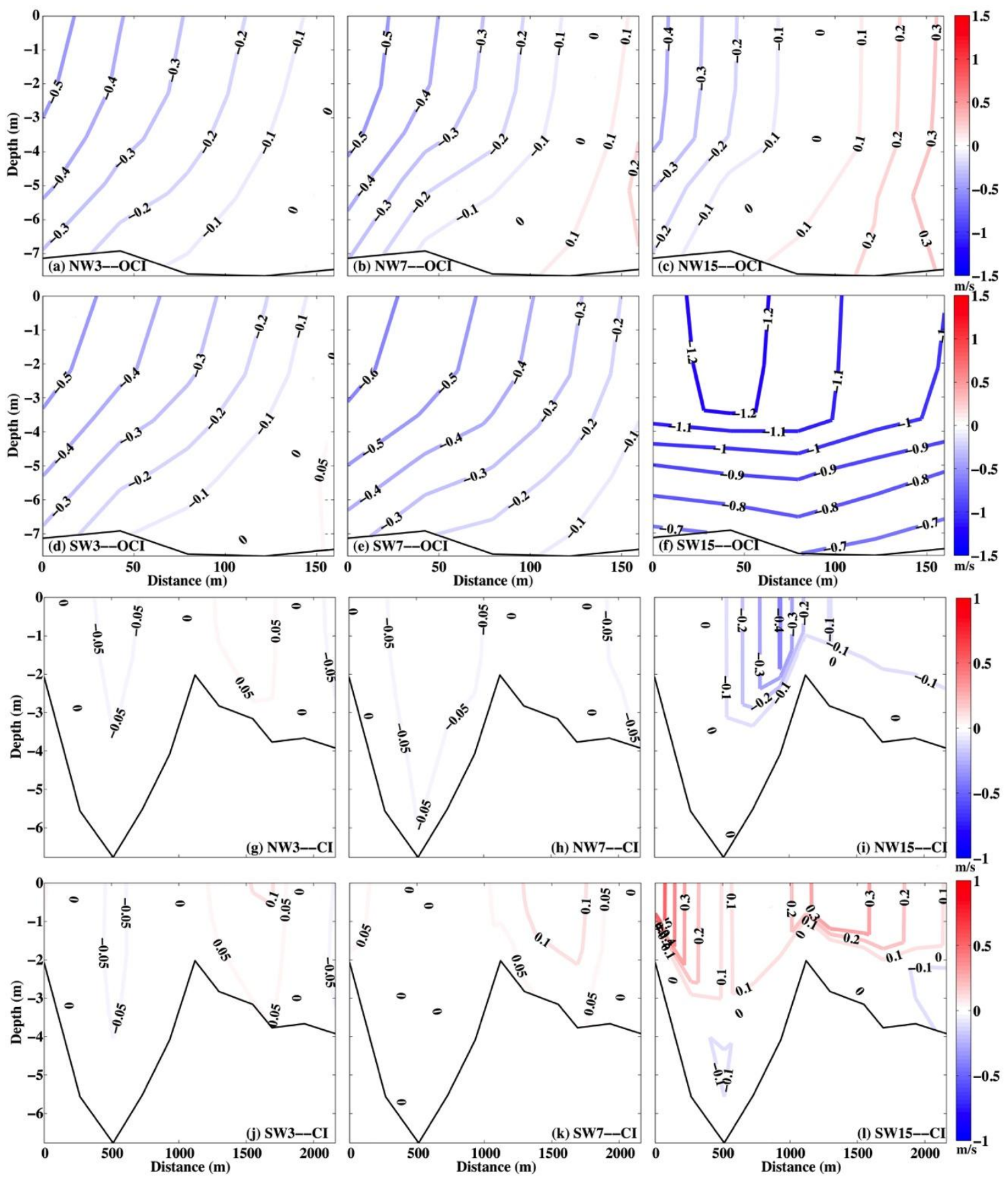

Fig. 8. Contours of current velocity at the OCI and CI transects with the interval of 0.05 and $0.1 \mathrm{~m} / \mathrm{s}$ excited by NW winds at: (a), (g) $3 \mathrm{~m} / \mathrm{s}$; (b), (h) $7 \mathrm{~m} / \mathrm{s}$; (c), (i) $15 \mathrm{~m} / \mathrm{s}$; and excited by SW winds at: (d), (j) $3 \mathrm{~m} / \mathrm{s}$; (e), (k) $7 \mathrm{~m} / \mathrm{s}$; (f), (l) $15 \mathrm{~m} / \mathrm{s}$, respectively. Positive/negative signals indicate onshore/offshore movement. 

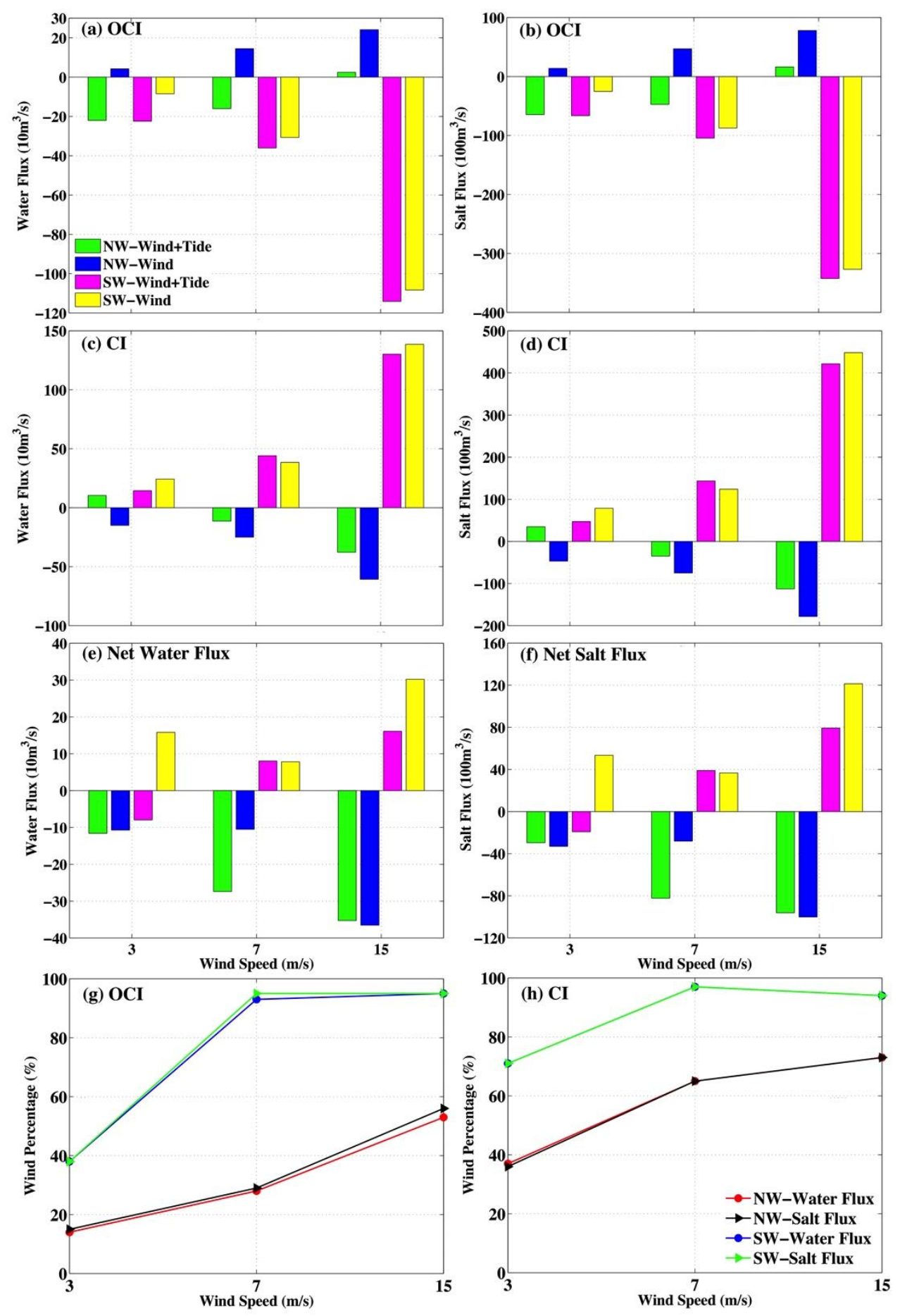

Fig. 9. Calculated water flux at (a) the OCI and (c) the CI; calculated salt flux across (b) the OCI and (d) the CI; its corresponding net water flux (e) and net salt flux (f) under different physical forcing. Net water flux and net salt flux is the sum of flow and salt for each inlet. Positive/negative signals indicate flow move into/out of the bays. The percentage of winds on water/salt flux at (g) the OCI and (h) the CI, respectively, under different physical forcing. 
Table 1

Model experiments.

\begin{tabular}{cccccc}
\hline & Name & Wind Direction & Wind Speed $(\mathrm{m} / \mathrm{s})$ & River Input & Tide \\
\hline Run 1 & No-flow & No wind & 0 & No & No \\
Run 2 & NW3 & Northwesterly & 3 & Yes & Yes \\
Run 3 & NW5 & Northwesterly & 5 & Yes & Yes \\
Run 4 & NW7 & Northwesterly & 7 & Yes & Yes \\
Run 5 & NW10 & Northwesterly & 10 & Yes & Yes \\
Run 6 & NW15 & Northwesterly & 15 & Yes & Yes \\
Run 7 & SW3 & Southwesterly & 3 & Yes & Yes \\
Run 8 & SW5 & Southwesterly & 5 & Yes & Yes \\
Run 9 & SW7 & Southwesterly & 7 & Yes & Yes \\
Run 10 & SW10 & Southwesterly & 10 & Yes & Yes \\
Run 11 & SW15 & Southwesterly & 15 & Yes & Yes \\
Run 12 & NW3_W & Northwesterly & 3 & Yes & No \\
Run 13 & NW7_W & Northwesterly & 7 & Yes & No \\
Run 14 & NW15_W & Northwesterly & 15 & Yes & No \\
Run 15 & SW3_W & Southwesterly & 3 & Yes & No \\
Run 16 & SW7_W & Southwesterly & 7 & Yes & No \\
Run 17 & SW15_W & Southwesterly & 15 & Yes & Yes \\
Run 18 & No-wind & No & 0 & & \\
\hline
\end{tabular}


Table 2

Corresponding statistics of different sensitivity tests on bottom roughness parameters at observed water elevation stations in the MCBs.

\begin{tabular}{|c|c|c|c|c|c|c|c|c|c|c|c|c|c|c|c|c|c|c|c|c|}
\hline \multirow[b]{2}{*}{$z_{0}(\mathrm{~m})$} & \multicolumn{4}{|c|}{ Ocean City Inlet } & \multicolumn{4}{|c|}{ Snug Harbor } & \multicolumn{4}{|c|}{ South Point } & \multicolumn{4}{|c|}{ Public Landing } & \multicolumn{4}{|c|}{ Harbor of Refuge } \\
\hline & $R$ & $\begin{array}{c}M A E \\
(\mathrm{~m})\end{array}$ & $\begin{array}{c}R M S D \\
(\mathrm{~m})\end{array}$ & $R S E$ & $R$ & $\begin{array}{c}M A E \\
(\mathrm{~m})\end{array}$ & $\begin{array}{c}R M S D \\
(\mathrm{~m}) \\
\end{array}$ & $R S E$ & $R$ & $\begin{array}{c}M A E \\
(\mathrm{~m})\end{array}$ & $\begin{array}{c}R M S D \\
(\mathrm{~m})\end{array}$ & $R S E$ & $R$ & $\begin{array}{c}M A E \\
(\mathrm{~m})\end{array}$ & $\begin{array}{c}R M S D \\
(\mathrm{~m})\end{array}$ & $R S E$ & $R$ & $\begin{array}{c}M A E \\
(\mathrm{~m}) \\
\end{array}$ & $\begin{array}{c}R M S D \\
(\mathrm{~m})\end{array}$ & $R S E$ \\
\hline 0.0031 & 0.91 & 0.09 & 0.12 & 0.25 & 0.58 & 0.09 & 0.11 & 0.68 & 0.54 & 0.14 & 0.16 & 2.47 & 0.47 & 0.13 & 0.15 & 2.47 & 0.88 & 0.14 & 0.17 & 0.40 \\
\hline 0.0032 & 0.92 & 0.09 & 0.11 & 0.22 & 0.73 & 0.08 & 0.09 & 0.52 & 0.72 & 0.14 & 0.16 & 2.28 & 0.74 & 0.12 & 0.14 & 2.10 & 0.93 & 0.12 & 0.15 & 0.31 \\
\hline 0.0033 & 0.96 & 0.10 & 0.12 & 0.25 & 0.82 & 0.07 & 0.08 & 0.41 & 0.83 & 0.15 & 0.16 & 2.51 & 0.86 & 0.14 & 0.15 & 2.37 & 0.94 & 0.14 & 0.16 & 0.37 \\
\hline 0.0034 & 0.96 & 0.07 & 0.08 & 0.12 & 0.80 & 0.07 & 0.09 & 0.43 & 0.71 & 0.09 & 0.11 & 1.13 & 0.73 & 0.08 & 0.09 & 0.95 & 0.93 & 0.10 & 0.12 & 0.21 \\
\hline 0.0035 & 0.95 & 0.09 & 0.11 & 0.22 & 0.86 & 0.08 & 0.09 & 0.44 & 0.76 & 0.16 & 0.17 & 2.74 & 0.76 & 0.15 & 0.16 & 2.65 & 0.94 & 0.14 & 0.16 & 0.38 \\
\hline 0.0036 & 0.92 & 0.10 & 0.12 & 0.27 & 0.84 & 0.08 & 0.09 & 0.51 & 0.78 & 0.07 & 0.08 & 0.64 & 0.80 & 0.05 & 0.07 & 0.55 & 0.93 & 0.09 & 0.11 & 0.19 \\
\hline 0.0037 & 0.96 & 0.07 & 0.08 & 0.12 & 0.80 & 0.07 & 0.08 & 0.41 & 0.78 & 0.10 & 0.11 & 1.24 & 0.80 & 0.09 & 0.10 & 1.04 & 0.93 & 0.10 & 0.12 & 0.20 \\
\hline 0.0038 & 0.95 & 0.09 & 0.11 & 0.23 & 0.81 & 0.07 & 0.08 & 0.39 & 0.74 & 0.11 & 0.12 & 1.43 & 0.80 & 0.09 & 0.11 & 1.20 & 0.94 & 0.10 & 0.12 & 0.20 \\
\hline 0.0039 & 0.96 & 0.10 & 0.12 & 0.26 & 0.86 & 0.07 & 0.08 & 0.37 & 0.82 & 0.14 & 0.15 & 2.12 & 0.83 & 0.13 & 0.14 & 1.98 & 0.95 & 0.12 & 0.14 & 0.29 \\
\hline
\end{tabular}

Orange squares: $z_{0}$ with best performance (lowest $M A E, R M S D$ and $R S E$ ) 
Table 3

Attenuations and time lags for observed and simulated water levels at diurnal frequencies.

\begin{tabular}{ccccc}
\hline \multirow{2}{*}{$\begin{array}{c}\text { Sites } \\
\text { from-to })\end{array}$} & $\begin{array}{c}\text { Attenuation } \\
\text { with } S D(\%)\end{array}$ & $\begin{array}{c}\text { Time Lag } \\
\text { (Hour) }\end{array}$ & $\begin{array}{c}\text { Attenuation } \\
\text { with } S D(\%)\end{array}$ & $\begin{array}{c}\text { Time Lag } \\
\text { (Hour) }\end{array}$ \\
\hline E1-E2 & 55.2 & 0.5 & 51.3 & 1.0 \\
E1-E3 & 75.5 & 5.0 & 64.5 & 4.0 \\
E1-E4 & -- & -- & -- & -- \\
E1-E5 & -- & -- & --- & -- \\
E5-E4 & 62.6 & 5.0 & 55.5 & 1.5 \\
E5-E3 & 60.7 & 5.5 & 50.9 & 3.5 \\
E5-E2 & -- & -- & -- & -- \\
E5-E1 & -- & -- & -- & -- \\
\hline E1-E2 & 57.6 & 0.5 & -- & -- \\
E1-E3 & 90.1 & 4.5 & -- & -- \\
E1-E4 & 92.5 & 7.0 & -- & -- \\
E1-E5 & 95.5 & 9.0 & -- & -- \\
\hline E5-E4 & 61.6 & 6.0 & -- & -- \\
E5-E3 & 62.7 & 6.5 & -- & - \\
E5-E2 & 70.7 & 7.5 & -- & - \\
E5-E1 & 85.3 & 11.0 & -- & \\
\hline
\end{tabular}

Blank: not available.

Purple squares: the calculated attenuations with SDs and time lags for model validation. Orange squares: the calculated attenuations with $S D$ s and time lags when closing the CI. Green squares: the calculated attenuations with $S D$ s and time lags when closing the OCI. E1 to E5 stand for water level gauges. E1: Ocean City Inlet; E2: Snug Harbor; E3: South Point; E4: Public Landing; E5: Harbor of Refuge. 
Table 4

Water flux and salt flux result for different experiments ${ }^{\mathrm{a}}$.

\begin{tabular}{|c|c|c|c|c|c|c|c|c|c|c|c|}
\hline Name & Inlet & $\begin{array}{c}\text { Surface } \\
\text { Flow }\end{array}$ & $\begin{array}{l}\text { Middle } \\
\text { Flow }\end{array}$ & $\begin{array}{c}\text { Bottom } \\
\text { Flow }\end{array}$ & $\begin{array}{c}\text { Surface } \\
\text { Salt }\end{array}$ & $\begin{array}{c}\text { Middle } \\
\text { Salt }\end{array}$ & $\begin{array}{c}\text { Bottom } \\
\text { Salt }\end{array}$ & Net Flow & Net Salt & $\begin{array}{l}\text { Total } \\
\text { Flow }\end{array}$ & Total Salt \\
\hline \multirow{2}{*}{ No_flow } & OCI & -64.52 & -2.58 & 13.84 & -1770.03 & -57.61 & 461.56 & -53.27 & -1366.08 & \multirow{2}{*}{0.71} & \multirow{2}{*}{460.80} \\
\hline & CI & -93.58 & 47.38 & 100.18 & -2952.02 & 1535.51 & 3243.39 & 53.98 & 1826.88 & & \\
\hline \multirow{2}{*}{ NW3 } & OCI & -119.87 & -47.04 & -53.34 & -3544.91 & -1385.55 & -1525.57 & -220.25 & -6456.03 & \multirow{2}{*}{-116.09} & \multirow{2}{*}{-2962.80} \\
\hline & CI & 26.83 & 23.90 & 53.43 & 928.32 & 798.78 & 1766.12 & 104.16 & 3493.23 & & \\
\hline \multirow{2}{*}{ NW5 } & OCI & -119.52 & -45.22 & -29.21 & -3601.92 & -1356.52 & -787.21 & -193.95 & -5745.64 & \multirow{2}{*}{-245.07} & \multirow{2}{*}{-7275.72} \\
\hline & CI & -45.84 & -7.99 & 2.70 & -1420.22 & -232.71 & 122.85 & -51.12 & -1530.08 & & \\
\hline \multirow{2}{*}{ NW7 } & OCI & -102.89 & -40.30 & -16.98 & -3098.28 & -1211.81 & -420.55 & -160.17 & -4730.64 & \multirow{2}{*}{-273.89} & \multirow{2}{*}{-8228.48} \\
\hline & CI & -71.99 & -27.38 & -14.35 & -2242.13 & -844.60 & -411.11 & -113.72 & -3497.84 & & \\
\hline \multirow{2}{*}{ NW10 } & OCI & -72.08 & -29.48 & 23.41 & -2162.26 & -884.29 & 702.37 & -78.14 & -2344.18 & \multirow{2}{*}{-285.64} & \multirow{2}{*}{-8984.16} \\
\hline & $\mathrm{CI}$ & -123.63 & -58.59 & -25.28 & -3956.18 & -1874.73 & -809.06 & -207.50 & -6639.98 & & \\
\hline \multirow{2}{*}{ NW15 } & OCI & -14.87 & -4.48 & 43.90 & -64.76 & 40.25 & 1655.63 & 24.56 & 1631.11 & \multirow{2}{*}{-352.67} & \multirow{2}{*}{-9612.72} \\
\hline & CI & -298.57 & -147.52 & 68.86 & -9079.14 & -4485.29 & 2320.60 & -377.23 & -11243.83 & & \\
\hline \multirow{2}{*}{ SW3 } & OCI & -133.56 & -47.96 & -42.54 & -4010.34 & -1429.90 & -1199.38 & -224.06 & -6639.62 & \multirow{2}{*}{-79.84} & \multirow{2}{*}{-1918.95} \\
\hline & CI & 78.50 & 27.67 & 38.05 & 2568.13 & 906.04 & 1246.50 & 144.22 & 4720.67 & & \\
\hline \multirow{2}{*}{ SW5 } & OCI & -147.94 & -53.14 & -43.57 & -4403.64 & -1574.91 & -1198.47 & -244.64 & -7177.02 & \multirow{2}{*}{-40.46} & \multirow{2}{*}{-478.23} \\
\hline & $\mathrm{CI}$ & 90.33 & 40.55 & 73.31 & 2966.71 & 1331.59 & 2400.49 & 204.18 & 6698.79 & & \\
\hline \multirow{2}{*}{ SW7 } & OCI & -188.26 & -79.06 & -93.31 & -5506.87 & -2298.08 & -2643.50 & -360.64 & -10448.44 & \multirow{2}{*}{80.35} & \multirow{2}{*}{3898.49} \\
\hline & CI & 220.38 & 96.58 & 124.03 & 7165.58 & 3142.53 & 4038.83 & 440.99 & 14346.94 & & \\
\hline \multirow{2}{*}{ SW10 } & OCI & -301.10 & -140.65 & -184.16 & -8700.63 & -4066.04 & -5273.07 & -625.91 & -18039.74 & \multirow{2}{*}{133.20} & \multirow{2}{*}{6627.48} \\
\hline & CI & 407.02 & 194.98 & 157.11 & 13218.25 & 6332.33 & 5116.65 & 759.11 & 24667.23 & & \\
\hline \multirow{2}{*}{ SW15 } & OCI & -520.54 & -257.06 & -363.22 & -15622.75 & -7716.69 & -10902.51 & -1140.82 & -34241.95 & & \\
\hline & CI & 980.68 & 488.01 & -166.76 & 31742.38 & 15795.68 & -5364.40 & 1301.93 & 42173.66 & 101.11 & 1931.11 \\
\hline No w & OCI & -136.62 & -51.32 & -47.77 & -4004.59 & -1488.01 & -1290.73 & -235.71 & -6783.33 & & \\
\hline 1No_WIII & CI & 43.06 & 32.97 & 65.96 & 1461.44 & 1090.78 & 2168.17 & 141.99 & 4720.38 & -93.15 & -2002.95 \\
\hline
\end{tabular}

${ }^{a}$ The unit for water flux and salt flux is $\mathrm{m}^{3} / \mathrm{s}$. Net flow and net salt is the sum of all the flow and all the salt from bottom to surface for each inlet. Total flow and total salt is the sum of flow and salt for both inlets in one case. Positive/negative signals mean the flux onshore/offshore movement. 